\title{
$\underline{\text { Molecular mechanisms of Evening Complex activity in Arabidopsis }}$
}

Catarina S. Silva ${ }^{1,2 \#^{*}}$, Aditya Nayak ${ }^{1 \#}$, Xuelei Lai ${ }^{1 \#}$, Veronique Hugouvieux ${ }^{1}$, Jae-Hoon Jung $^{3}$, Agnès Jourdain ${ }^{1}$, Irene López-Vidriero ${ }^{4}$, Jose Manuel Franco-Zorrilla ${ }^{4}$, François Parcy $^{1}$, Kishore Panigrahi ${ }^{5}$, Philip A. Wigge ${ }^{3}$, Max Nanao $^{2}$ and Chloe Zubieta ${ }^{1 *}$

\# these authors contributed equally to the work

* to whom correspondence should be addressed

${ }^{1}$ Laboratoire de Physiologie Cellulaire and Végétale, Univ. Grenoble Alpes/CNRS/CEA/INRA/BIG, 17 rue des Martyrs, 38054 Grenoble, France.

${ }^{2}$ European Synchrotron Radiation Facility, Structural Biology Group, 71 Avenue des Martyrs, F-38000 Grenoble.

${ }^{3}$ Sainsbury Laboratory, Cambridge University, 47 Bateman Street, Cambridge CB2 1LR, UK.

${ }^{4}$ Genomics Unit, Centro Nacional de Biotecnología-Consejo Superior de Investigaciones Científicas, C/ Darwin 3, 28049 Madrid, Spain.

${ }^{5}$ Plant BIology Lab, SBS, NISER, PO: Jatnai, Dist - Khurda, Odisha 752050, India 


\title{
Significance Statement
}

Circadian gene expression oscillates over a $24 \mathrm{hr}$. period and regulates many genes critical for growth and development. In plants, the Evening Complex (EC), a three-protein repressive complex made up of LUX ARRYTHMO, EARLY FLOWERING 3 and EARLY FLOWERING 4, acts as a key component of the circadian clock and is a regulator of thermomorphogenic growth. However, the molecular mechanisms of complex formation and DNA-binding have not been identified. Here we determine the roles of each protein in the complex and present the structure of the LUX DNA-binding domain in complex with DNA. Based on these data, we used structure-based protein engineering to produce a version of the EC with altered in vitro and in vivo activity. These results demonstrate that the EC can be modified to alter plant growth and development at different temperatures in a predictable manner.

\begin{abstract}
$\underline{\text { Abstract }}$
The Evening Complex (EC), composed of the DNA-binding protein LUX ARRHYTHMO (LUX) and two additional proteins, EARLY FLOWERING 3 (ELF3) and ELF4, is a transcriptional repressor complex and a core component of the plant circadian clock. In addition to maintaining oscillations in clock gene expression, the EC also participates in temperature and light entrainment and regulates important clock output genes such as PHYTOCHROME INTERACTING FACTOR 4 (PIF4), a key transcription factor involved in temperature dependent plant growth. These properties make the EC an attractive target for altering plant development through targeted mutations to the complex. However, the molecular basis for EC function was not known. Here we show that binding of the EC requires all three proteins and that ELF3 decreases the ability of LUX to bind DNA whereas the presence of ELF4 restores interaction with DNA. To be able to manipulate this complex, we solved the structure of the DNA-binding domain of LUX bound to DNA. Using structurebased design, a LUX variant was constructed that showed decreased in vitro binding affinity but retained specificity for its cognate sequences. This designed LUX allele modulates hypocotyl elongation and flowering. These results demonstrate that modifying the DNAbinding affinity of LUX can be used to titrate the repressive activity of the entire EC, tuning growth and development in a predictable manner.
\end{abstract}

Keywords: circadian clock, gene regulation, Evening Complex, protein-DNA complex

\section{Introduction}

The circadian clock provides endogenous rhythms that allow plants to anticipate and react to daily environmental changes. Many processes such as photosynthesis and growth occur in a rhythmic manner over a 24-hour cycle (1-3). These circadian rhythms persist even in the absence of light/dark cues due to internal repeating oscillations of core clock genes that in turn modulate gene expression patterns of many different output pathways (4). In Arabidopsis, the circadian clock consists of three main interacting transcription-translation feedback loops: the morning, central and evening loops. Components of these interlocking 
feedback loops repress each other's expression resulting in rhythmic gene expression over a 24-hr period (for review see,(3, 5-7)). The Evening Complex, composed of LUX, ELF3 and ELF4, is a core component of the circadian clock (8-12). The expression patterns of the three genes overlap, peaking at dusk. Thus, the EC has maximum activity at the end of the day and early night, acting to repress expression of the circadian morning loop genes PSEUDORESPONSE REGULATOR 7 and 9 (PRR7 and 9), the central loop gene CCA1 and the evening loop genes GIGANTEA (GI) and LUX itself (12-15).

Loss-of-function mutations in elf3, elf4 or lux give rise to arrhythmic circadian outputs with alterations in many developmental pathways (9, 16-18). This results in phenotypes including elongated hypocotyls and early flowering regardless of day length or ambient temperature $(9,12,16-19)$. In addition, natural variation in EC components ELF3 and LUX has been shown to give rise to altered thermal responsive growth not only in Arabidopsis but also in crop plants (20-23). Lack of thermoresponsiveness, elongated hypocotyls and early flowering in EC mutants is hypothesized to be due in large part to misregulation of the circadian output pathway involving the bHLH transcription factor PHYTOCHROME INTERACTING FACTOR 4 (PIF4) (15), a master regulator of cell elongation, thermoresponsive growth and the shade avoidance response (19, 24-28).

The repressive regulatory activity of the EC is temperature dependent, making it a node that integrates both circadian gene regulation and environmental information to control growth and developmental pathways in the plant (14, 20, 29). Extensive ChIP-seq experiments performed at different temperatures demonstrated that the binding sites for LUX, ELF4 and ELF3 extensively overlap and that the strength of binding for the EC is dependent on temperature, with weaker binding of the complex at higher temperatures (15). This raises the intriguing possibility that the EC can be used to alter plant growth and development and may be an attractive target for crop improvement (29). The underlying mechanisms that determine EC complex formation and DNA-binding, however, remained to be elucidated. Here, we determine the role of each protein in EC formation, address the molecular determinants of DNA-binding affinity and specificity and demonstrate that alterations in the DNA-binding affinity of LUX can predictably alter EC function in planta.

\section{$\underline{\text { Results }}$}

\section{Role of LUX, ELF3 and ELF4 in complex formation and DNA-binding}

Of the three EC proteins, only LUX is able to directly bind DNA, however complex formation is necessary for full EC activity based on the similar phenotypes of elf3, elf4 and 
lux mutants $(9,16-18)$. In order to investigate the roles of the different EC components in protein-protein interactions and DNA-binding, in vitro refolding of the full EC and subcomplexes was performed due to low solubility of ELF3 under native conditions. Stepwise dialysis against decreasing urea concentrations was used to form the respective complexes. To confirm production of active EC and to assess the DNA-binding affinity of the complex, EMSAs were performed using a 36 base pair (bp) fragment from the PRR9 promoter containing a previously characterised LUX binding site (LBS) (10). As shown in Figure 1A, ELF3 and ELF4 alone did not interact with DNA, as expected, since neither protein is predicted to have a DNA-binding domain. Addition of ELF4 to a solution containing LUX had no effect on LUX binding. However, titrating in ELF3 while keeping LUX and ELF4 concentrations constant resulted in the disappearance of the LUX-DNA band and the appearance of a higher molecular weight band corresponding to the EC bound to DNA (Figure 1A, left). Interestingly, without ELF4 present, LUX-ELF3 exhibited highly attenuated DNA-binding, with the appearance of a free DNA band that increases in intensity with increasing ELF3 concentration. No higher molecular weight bands were observed with LUX-ELF3 alone (Figure 1A, right). These results suggest that ELF3 modulates efficient binding of LUX to DNA and that ELF4 is able to restore DNA-binding competency to the complex (Figure 1B).

\section{LUX binds DNA with high affinity independently of the EC}

In order to determine whether LUX alone was sufficient to confer DNA-binding affinity and specificity, we analysed the DNA-binding activity of LUX using protein-binding microarrays (PBM) and the full-length protein $\left(\mathrm{LUX}^{\mathrm{FL}}\right)$ and DNA-binding MYB domain (residues 139-200, LUX ${ }^{\mathrm{MYB}}$ ) tagged with an $\mathrm{N}$-terminal maltose binding protein. Experiments were performed and analysed as previously described $(30,31)$. $\mathrm{LUX}^{\mathrm{FL}}$ yielded over 100 high affinity binding 8-mers with E-scores over 0.45 , indicative of tight binding. Most motifs correspond to variations of the sequence "AGAT(A/T)CG" as previously determined in vivo (10) (Figure 2A). The isolated DBD LUX ${ }^{\mathrm{MYB}}$ bound with lower affinity producing consensus motifs with E-scores mainly below 0.40, with only two 8-mers identified with E-scores above 0.45. (SI Figure 1).

As LUX has only a single MYB domain and neither ELF3 nor ELF4 directly binds DNA, the absolute binding affinities of untagged $\mathrm{LUX}^{\mathrm{FL}}$ and $\mathrm{LUX}^{\mathrm{MYB}}$ were assayed to determine whether this single domain would be able to target the EC to its cognate binding sites. To confirm the affinity of LUX-DNA interactions, DNA sequences with variations of 
the LBS were tested using electrophoretic mobility shift assays (EMSAs) with varying protein concentrations. Surprisingly, $\mathrm{LUX}^{\mathrm{MYB}}$ exhibited higher affinity compared to the full-length protein for all DNA probes tested with $K_{d}$ 's ranging from $6.5 \mathrm{nM}$ to $43 \mathrm{nM}$ (Figure 2B and Table 1). The full-length protein exhibited lower affinity over the sequences tested, with $K_{d}$ 's in the 90-180 nM range (Figure 2C and Table 1). All $K_{d}$ measurements were performed on untagged proteins, unlike the PBM experiments. The PBM result indicating a lower affinity of $\mathrm{LUX}^{\mathrm{MYB}}$ for DNA is thus likely due to the N-terminal MBP fusion, which may occlude the DNA-binding site and suggests that large protein fusions close to the N-terminus of the MYB domain negatively impacts DNA-binding. These data demonstrate that LUX is able to bind with high affinity to its cognate sites in the low nanomolar range and that this tight binding is likely sufficient to target the entire EC to its cognate sites.

\section{The GARP family signature motif in LUX is required for base read-out}

Having determined the in vitro binding specificity and affinity of LUX and LUX ${ }^{\mathrm{MYB}}$ with DNA, we sought to reveal the molecular determinants for DNA-binding. LUX ${ }^{\mathrm{MYB}}$ was crystallized and the atomic structure determined in complex with a 10-mer dsDNA, 5'TAGATACGCA containing the core binding motif (underlined) determined from the PBM experiments and a second DNA sequence 5'-TATATTCGAA which lacks the highly conserved guanine at the beginning of the LBS and replaces the adenine with a thymine at position 4, a conservative change in the LBS consensus sequence GAT(A/T)CG (SI Table 1). For both structures, $\mathrm{LUX}^{\mathrm{MYB}}$ adopts a classic three-helix bundle conformation characteristic of MYB domains (Figure 3). The MYB hydrophobic core usually consists of three regularly spaced residues, most often tryptophans, with a spacing of 18 or 19 amino acids (32). In $\mathrm{LUX}^{\mathrm{MYB}}$, however, the second and third tryptophan residues are replaced by a proline (Pro171) and leucine (Leu192) based on structural alignments. Proline at position 171 creates a tight turn before helix 2 and brings the helix in close proximity to the DNA. A proline at this position is also conserved in other plant MYB proteins such as the structural characterized transcription factor, AtARR10 (Figure 3B). Interestingly, in the lux-4 null mutant, Pro171 is replaced by a leucine residue, suggesting the tight turn before helix 2 is required for proper interaction of the protein with DNA. The hydrophobic core in LUX ${ }^{\mathrm{MYB}}$ is stabilized by additional hydrophobic interactions including edge-to-face interactions of Phe157 (helix 1) and Tyr195 (helix 3), $\pi$ stacking of Trp149 (helix 1) with His191 (helix 3) and edge-to-face interactions of His191 and Phe157 (Figure 3A). The protein sequesters DNA primarily through helix 3 that lies in the major groove and contains a plant-specific 
GARP family signature motif, $\mathrm{SH}(\mathrm{A} / \mathrm{L}) \mathrm{QK}(\mathrm{F} / \underline{\mathrm{Y}})$ (16). Examination of the electrostatic surface of the protein demonstrates a highly electropositive face that acts as the main DNAbinding surface (Figure 3A).

Helix 2 and 3 form a helix-turn-helix motif, constituting an electropositive groove for the negatively charged DNA and acting as the primary interface with the LBS. Residues from helix 3 account for the majority of the direct base readout and also contribute sugar-phosphate backbone interactions between the protein and DNA (Figure 4A). While no residues in helix 1 directly interact with the DNA, Arg146, part of the unstructured N-terminal extension, intercalates into the minor groove and interacts largely via van der Waal's forces and a watermediated hydrogen bonding network with adenine and thymine/guanine of the bound DNA (TAGATACGA and TATATTCGAA) (Figure 4B). Interestingly, the Arg146 residue adopts different conformations in the two structures with different hydrogen bonding networks, suggesting plasticity in how Arg146 binds DNA.

As Arg146 seems to act as a general "clamp" targeting the DNA minor groove, this residue was targeted for mutagenesis. The R146A mutation in both the LUX ${ }^{\mathrm{MYB}}$ and fulllength constructs was assayed for DNA-binding by EMSA. As predicted, the R146A mutation decreased the binding affinity for both $\mathrm{LUX}^{\mathrm{MYB}}$ and the full-length protein, albeit with a greater effect depending on the DNA sequence (Table 1).

\section{Tuning EC activity in planta}

Based on the in vitro results presented above, the ability to alter EC activity through changes in the DNA-binding affinity of LUX was investigated. We hypothesised that decreasing LUX DNA-binding affinity would result in less active EC target gene repression and a warm temperature phenotype intermediate between wild type and the lux null mutant. To test this, we examined hypocotyl length under short day conditions at $22^{\circ} \mathrm{C}$ and $27^{\circ} \mathrm{C}$ and flowering time under long day conditions at $22^{\circ} \mathrm{C}$. The null mutant, $l u x-4$, in the Arabidopsis Col-0 background was transformed with either wild type $L U X$ or $L U X^{R I 46 A}$ under the control of its native promoter and hypocotyl length was measured for three independent homozygous lines for each genotype. Transformation with the $p L U X:: L U X$ construct resulted in complementation based on hypocotyl length (Figure 5 A-C) and on flowering time, measured as the number of rosette leaves at time of bolting, (Figure 5 D, E). This phenotype was recapitulated in subsequent generations.

In contrast, $L U X^{R 146 A}$ was not able to completely rescue the lux-4 mutation and an intermediate phenotype between wild type and $l u x-4$ was observed for both hypocotyl length 
and flowering time (Figure 5 A-E). Temperature responsive growth was still observed in $L U X^{R 146 A}$ but was more attenuated than in wild type or $l u x-4$ complemented with the wild type gene (Figure 5C). Taken together, these data show that reduction in the binding affinity by the $\mathrm{LUX}^{\mathrm{R} 146 \mathrm{~A}}$ mutation, as demonstrated in vitro, has a predictable in vivo effect of titrating activity of the entire EC.

\section{PIF4 expression is misregulated in $L U X^{R 146 A}$}

PIF4 is a master regulator of cell elongation, hypocotyl length and integrates light and temperature signals for plant growth. The PIF4 promoter contains a consensus LBS sequence (GAT(A/T)CG) and PIF4 is a target of the EC based on ChIP-seq and RNA-seq experiments $(12,14,15)$. Therefore, the expression levels of PIF4 were examined by RT-qPCR at 4-hour intervals over a $24 \mathrm{hr}$ period in the different genotypes (Figure 5F). In wild type Arabidopsis, PIF4 expression is under circadian control and oscillates over a $24-\mathrm{hr}$ period, with a strong repression at ZT12 when EC expression peaks, as shown in Figure 5F. PIF4 expression increases as EC expression decreases, peaking during the day. In the lux-4 mutant, PIF4 expression levels are elevated with respect to WT and the sharp decrease in PIF4 expression at dusk (ZT8-ZT12) is attenuated. The lux-4 mutant is complemented by $p L U X:: L U X$ based on hypocotyl length and flowering time, however some misregulation of PIF4 is still observed as wild type levels of PIF4 repression are not fully restored. This misregulation is more evident in $\operatorname{lu} x-4 p L U X:: L U X^{R 146 A}$ and is consistent with the observed intermediate phenotype between wild type and $l u x-4$. Expression of PIF4 was elevated with respect to wild type in $L U X^{R 146 A}$ and did not exhibit the sharp decrease in expression between ZT8 and ZT12, similar to the lux-4 mutant. Overall, PIF4 expression was elevated in the $L U X^{R I 46 A}$ lines compared to wild type, but lower than in the lux-4 mutant suggesting that $\mathrm{LUX}^{\mathrm{R} 146 \mathrm{~A}}$ triggers a misregulation of PIF4. It is likely that the observed phenotypes are due at least in part to changes in PIF4 expression in the different mutant lines.

\section{Discussion}

The EC plays an important role in the circadian clock, functioning to connect the evening and morning loops by forming a key circuit in the plant circadian system (33). In addition, the EC is ideally positioned to act as a hub for integrating environmental cues and relaying this information directly to growth and developmental pathways through direct effects on target genes including PIF4, a master regulator of thermosensory growth, plant immunity and reproductive development $(26,34,35)$. Using the EC to tune temperature 
sensitive growth is an attractive goal requiring an understanding of the molecular basis of EC formation and activity. However, this was poorly defined. To address this deficit we sought to provide a molecular model of LUX, ELF3 and ELF4 interactions in EC formation and to define the residues critical for DNA-binding.

Regulation of target genes requires the full EC as suggested by the similar phenotypes of lux-4, elf3-1 and elf4 mutants $(17,36-38)$, however only LUX possesses a DNA binding domain. Indeed, LUX binding to DNA in vivo was observed in the elf3-1 background, demonstrating that complex formation is not required for LUX DNA-binding (15) but is required for regulation. LUX and ELF3 have been shown to interact in yeast two-hybrid assays and in vivo (12). Here, we demonstrate that in vitro, ELF3 is able to impede LUXDNA interactions, at least for certain LBS sequences, suggesting the formation of a complex that is not competent to bind DNA. This type of sequestering role of ELF3 has been observed for ELF3-PIF4 interactions and may be a general function of ELF3 in other protein complexes (39). We further demonstrate that ELF4 modulates the activity of ELF3 and restores DNA-binding competency to the LUX-ELF3-ELF4 complex (EC), highlighting its crucial role in the EC. Indeed, previous modelling studies of the contributions to EC activity suggested that ELF4 transcript levels are as powerful a predictor of EC target gene repression as using the full EC ( $L U X, E L F 3$ and ELF4 transcript levels) and more predictive than ELF3 alone (15). Thus, only with all three components, LUX, ELF3 and ELF4, do both DNAbinding and target gene regulation occur.

Based on the in vitro and structural studies presented here, LUX provides the specificity and affinity necessary to target the entire EC to its cognate binding sites. The MYB domain is able to perform direct base read-out of the core LBS. The plant specific signature sequence, $\mathrm{SH}(\mathrm{A} / \mathrm{L}) \mathrm{QK}(\mathrm{F} / \underline{\mathrm{Y}})$ of helix 3, provides the majority of direct interactions via the major groove. In addition, an N-terminal arginine, Arg146, part of a flexible extension, is important for intercalation into the minor groove and acts as a DNA clamp. Arginine residues in flexible extensions are found in many other structurally diverse TFs including homeodomain TFs and MADS TF family members $(40,41)$. While these arginine residues are likely important for DNA shape readout by intercalating into the minor groove (42), they are often not required for direct base-readout and may offer a general way to decrease DNA binding affinity while maintaining specificity for other TF families, although this remains to be tested.

Arg146 of LUX was mutated to alanine in order to decrease the DNA-binding affinity of the EC for its cognate sites while still retaining specificity. Based on in vitro assays, we 
predicted dampened but not abolished EC activity in planta. Indeed, at $22^{\circ} \mathrm{C}$ an intermediate early flowering phenotype between wild type and lux-4 was observed for lux-4 plants transformed with $p L U X:: L U X^{R 146 A}$. EC activity is greatly reduced at $27^{\circ} \mathrm{C}$ and this was reflected in the similar phenotypes of wild type and the lux-4 transformed lines. The R146A mutation resulted in accelerated growth but still retained thermo-response.

PIF4 is an important direct target of the EC implicated in hypocotyl elongation and thermoresponsive growth and a target of the EC $(15,26,35)$. PIF4 expression was higher in the lux-4 pLUX::LUX $X^{R 146 A}$ plants as compared to wild type and these plants phenocopy mild PIF4 over-expressors which have an early flowering phenotype and elongated hypocotyls at $22^{\circ} \mathrm{C}(35)$. The peak of PIF4 expression was similar for wild type and lux-4 pLUX::LUX ${ }^{R I 46 A}$, however the characteristic strong decrease in PIF4 expression between ZT8 and ZT12, which coincides with maximum EC expression, was less apparent, likely due to the decreased affinity of the R146A mutation for its LBS.

The roles of the EC as a core clock component and as a direct regulator of PIF4 make it an attractive target for tuning plant development. The EC is present in basal plants such as mosses to higher flowering plants, suggesting an evolutionarily conserved function. Altering EC activity via structure-based design or directed evolution is a potential strategy to modify plant growth and flowering pathways in not only model plants but also crop species. Directed evolution strategies have been used to alter transcription factor properties including changing DNA-binding specificities and increasing/decreasing DNA-binding affinity (43-45). The data presented here demonstrate that rational design strategies targeting amino acids important for LUX binding can be used to tune the activity of the entire EC, resulting in plants with a predictable phenotype, suggesting a viable method for rational engineering of plant development.

\section{Materials and Methods}

\section{Protein binding microarrays}

LUX (LUX FL; TAIR At3g46640.1) and LUX ${ }^{\text {MYB }}$ (amino acid residues 139-200wer cloned into the pETM41 vector and recombinant proteins were expressed as described (30, 31). DNA-binding specificities were determined using protein binding microarrays (PBM11), as previously described $(30,31)$.

\section{Protein expression}

$L U X, L U X^{M Y B}$ and $E L F 4$ were cloned into the expression vector pESPRIT002 $(46,47)$, expressed and purified using standard protocols $(46,47)$. Seleno-methionine (SeMet) derived LUX $^{\mathrm{MYB}}$ protein was produced according to standard protocols (48). 
Full-length ELF3 (TAIR At2g25930.1) was cloned into the pACEBac1(49) vector and produced in $S f 21$ insect cells (Invitrogen) using the baculovirus expression system.

\section{Protein Purification}

$\mathrm{LUX}^{\mathrm{FL}}, \mathrm{LUX}^{\mathrm{MYB}}$ and SeMet $\mathrm{LUX}^{\mathrm{MYB}}$ proteins were isolated following the same purification protocol. Harvested cells were resuspended in $200 \mathrm{mM}$ CAPS pH 10.5, $500 \mathrm{mM}$ $\mathrm{NaCl}, 1 \mathrm{mM}$ TCEP, sonicated, centrifuged and the soluble proteins purified by Ni-affinity chromatography. The N-terminal 6xHis tag was cleaved with TEV protease and the protein further purified using a heparin $\left(\mathrm{LUX}^{\mathrm{MYB}}\right)$ or Superdex $200\left(\mathrm{LUX}^{\mathrm{FL}}\right)$ column (GE Healthcare).

For ELF4 protein, harvested cells were resuspended in $20 \mathrm{mM}$ Tris $\mathrm{pH} 8.0,500 \mathrm{mM}$ $\mathrm{NaCl}, 1 \mathrm{mM}$ TCEP. Purification was as per $\mathrm{LUX}^{\mathrm{FL}}$.

For ELF3 the protein was purified from $8 \mathrm{M}$ Urea using a Ni-Sepharose HighPerformance resin column. The protein was refolded in the presence of LUX and ELF4 through step-wise dialysis from $8 \mathrm{M}$ to $0 \mathrm{M}$ urea.

\section{Protein crystallisation and data collection}

Protein-DNA complexes were crystallised using the hanging drop method as previously described (50).

Diffraction data were collected at $100 \mathrm{~K}$ at the European Synchrotron Radiation Facility (ESRF), Grenoble France. Data collection and refinement statistics are given in SI Table 1. The structures are deposited under PDB codes 5LXU and 6QEC.

\section{Sequence Alignments}

Structure-based sequence alignments were performed using the server PROMALS3D (51). All structures were aligned with TM-align using the default parameters (52).

\section{Electrophoretic Mobility Shift Assays (EMSAs)}

DNA was Cy5 labelled for visualisation and used at a final concentration of $10 \mathrm{nM}$ for PAGE and $30 \mathrm{nM}$ for agarose gels. Protein and DNA were incubated at room temperature in binding buffer (10 mM Tris $\mathrm{pH}$ 7.0, $50 \mathrm{mM} \mathrm{NaCl}, 1 \mathrm{mM} \mathrm{MgCl} 2,1 \mathrm{mM}$ TCEP, 3\% glycerol, $28 \mathrm{ng} / \mu \mathrm{L}$ herring sperm DNA, $20 \mu \mathrm{g} / \mathrm{mL}$ BSA, 2.5\% CHAPS and $1.25 \mathrm{mM}$ spermidine) and protein-DNA complexes run on a $8 \%$ polyacrylamide gel using TBE buffer $0.5 \mathrm{x}$ in nondenaturing conditions at $4^{\circ} \mathrm{C}$.

Protein concentration was varied from $0 \mathrm{nM}$ to $1000 \mathrm{nM}$ for $\mathrm{LUX}^{\mathrm{MYB}}$ and $\mathrm{LUX}^{\mathrm{FL}}$ experiments. For LUX-ELF3 and LUX-ELF3-ELF4 experiments, all tested complexes were reconstituted by mixing the proteins of interest in $6 \mathrm{M}$ urea followed by a step-wise dialysis to $0 \mathrm{M}$ urea. LUX and ELF4 concentrations were constant while the ELF3 concentration was varied from $220 \mathrm{nM}$ to $2.2 \mu \mathrm{M}$. Proteins and DNA were incubated at room temperature and protein-DNA complexes run on a $2 \%$ agarose gel using TBE buffer $0.5 x$ in non-denaturing conditions at $4^{\circ} \mathrm{C}$.

\section{Plant material and cultivation conditions}

For qPCR and hypocotyl measurements material was collected from 7-days old seedlings grown in FitoClima D1200 (Aralab) growth chambers, at $22^{\circ} \mathrm{C}(\mathrm{SD}, 8 \mathrm{~h}$ light/16h dark). Hypocotyl measurements were performed on the T2 generation of plants with 15-25 plants for each independent line. For flowering phenotype analysis, primary transformants were selected for the transgene and sown on soil and transferred to $\mathrm{LD}$ conditions after stratification $\left(4^{\circ} \mathrm{C}, 3\right.$ days). Flowering time was 
determined in randomly distributed plants according to number of rosette leaves at the time of bolting (10 plants for wild type, lux-4, lux-4 pLUX::LUX ${ }^{R 146 A}$ and lux-4 pLUX::LUX).

\section{Plasmid construction and generation of transgenic plants}

For the lux-4 pLUX::LUXR146A, lux-4 pLUX::LUX constructs, a 800bp upstream fragment of $L U X$ was PCR-amplified from genomic DNA. Full length CDS of $L U X$ and $L U X^{R 146 A}$ were PCR-amplified from the pESPRIT002 expression vector containing the respective CDS with an N-terminal FLAG tag added (SI Figure 2). NEBuilder ${ }^{\circledR}$ HiFi DNA Assembly Kit (E2621S, NEB) was used for assembly with the vector backbone (pFP101 containing the At2S3 promoter driven GFP for selection of transformants)(57). For a list of primers see SI Table 2. Transgenic plants were generated using the floral dip method (58).

\section{RNA isolation and quantitative PCR}

Plants were grown under short day conditions (8L:16D) and samples were harvested in intervals of 4 hours. 8-10 seedlings were harvested for each line at each time point. Total RNA was extracted using RNeasy Plant mini kit (Qiagen) according to manufacturer's instructions. Total RNA $(1 \mu \mathrm{g})$ was treated with DNaseI (Roche) qRT-PCR was done using iTaq ${ }^{\circledR}$ Universal SYBR $\AA$ Green One-Step Kit from Bio-Rad following manufacturer's protocol. For the list of primers see SI Table 2. Expression of PIF4 in different plant lines was determined through qRT-PCR with PP2A used as a control. qRT-PCR measurements were performed with a Bio-Rad CFX connect Real-Time system. Quantification was performed with the relative $-\Delta \mathrm{Ct}$ method, using $P P 2 A$ for normalization. All quantification and statistical analysis were performed using CFX Maestro $^{\text {TM }}$ software (Bio-Rad).

Details for Materials and Methods are given in accompanying SI.

\section{Acknowledgments}

We would like to acknowledge Darren Hart and Philippe Mas for the pESPRIT002 vector and the ESRF beamline staff of ID29, ID23-2 and the EMBL HTX Lab Funding was from the European Community's Seventh Framework Programme (FP7/2007-2013) under BioStruct-X (grant agreement $\mathrm{N}^{\circ} 283570$ ), the Raman Chaprak Fellowship (to AN), CEA Irtelis program (AN, CZ), ATIP-Avenir (CZ), GRAL (ANR-10-LABX-49-01) (CZ, VH, FP) and the Spanish MINECO grant BIO2017-86651-P (AEI/FEDER) to JMF-Z 


\section{TABLES}

Table 1. DNA-binding affinities of $L U X^{M Y B}$ and $L U X^{F L}$ and respective mutants.

\begin{tabular}{|l|l|l|l|l|}
\hline $\begin{array}{l}\text { LUX binding site 8- } \\
\text { mer motifs }\end{array}$ & $\mathrm{LUX}^{\mathrm{MYB}}(\mathrm{nM})$ & $\mathrm{LUX}^{\mathrm{FL}}(\mathrm{nM})$ & $\begin{array}{l}\mathrm{LUX}^{\mathrm{MYB}} \\
\mathrm{R} 146 \mathrm{~A}(\mathrm{nM})\end{array}$ & $\begin{array}{l}\text { LUX } \\
\text { R146A }\end{array}$ \\
\hline $\begin{array}{l}\text { AGATTCGA } \\
(P R R 9)\end{array}$ & $37 \pm 2.9$ & $93 \pm 5.8$ & $50 \pm 2.4$ & $105 \pm 11.8$ \\
\hline $\begin{array}{l}\text { AGATACGC } \\
\text { (crystal) }\end{array}$ & $6.5 \pm 1.4$ & $98 \pm 2.9$ & $50 \pm 1.8$ & $336 \pm 4.8$ \\
\hline AAGATCTT & $14 \pm 1.8$ & $93 \pm 3.5$ & $63 \pm 3.1$ & $204 \pm 6.7$ \\
\hline GGATCCGA & $17 \pm 2.1$ & $118 \pm 10.6$ & $120 \pm 1.0$ & $164 \pm 4.2$ \\
\hline $\begin{array}{l}\text { ATATTCGA } \\
\text { (crystal) }\end{array}$ & $43 \pm 4.2$ & $178 \pm 3.5$ & $137 \pm 13.0$ & $\mathrm{nd}^{*}$ \\
\hline
\end{tabular}

* binding was too weak to measure

\section{Figure Legends}

Figure 1. EC and subcomplexes interactions with DNA. A. EMSAs of LUX-ELF3 and the $\mathrm{EC}$, in $2 \%$ agarose gels. DNA concentration was $30 \mathrm{nM}$. (Left) Reconstitution of the EC with LUX and ELF4 concentrations held constant at $200 \mathrm{nM}$ and $1000 \mathrm{nM}$, respectively and increasing ELF3 concentrations $(220 \mathrm{nM}, 450 \mathrm{nM}, 890 \mathrm{nM}, 1.3 \mu \mathrm{M}, 1.8 \mu \mathrm{M}$ and $2.2 \mu \mathrm{M})$. (Right), LUX-ELF3 interactions, with LUX concentration kept at $200 \mathrm{nM}$. With increasing ELF3 concentration, the free DNA band increases in intensity. B. Schematic depiction of LUX, ELF3 and ELF4 interactions and DNA-binding.

Figure 2. LUX-DNA interactions. A. High scoring protein binding microarray-derived logos for LUX. Three logos are presented including the LBS consensus (left), the PRR9 promoter LBS sequence (middle) and a high scoring PBM sequence (right). B. Representative gel electrophoretic mobility shift assays (EMSAs) for LUX ${ }^{\mathrm{MYB}}$. DNA concentration was constant with protein concentration increasing from 0 to $1000 \mathrm{nM}$. The DNA sequences used correspond to the above motifs in (A). Free DNA is indicated by an arrow and protein-DNA complexes are indicated with stars. One star corresponds to one molecule of protein bound, two stars indicates multiple non-specifically bound protein molecules at high protein concentrations. C. Representative EMSA for $\mathrm{LUX}^{\mathrm{FL}}$, labelled as per (B).

Figure 3. Structure of $\mathrm{LUX}^{\mathrm{MYB}}$ in complex with DNA. A. Left, overlay of $\mathrm{LUX}^{\mathrm{MYB}}$ structures in cyan (PDB 5LXU) and yellow (PDB 6QEC) with the hydrophobic core residues displayed as sticks and colored by atom with carbons in cyan (only 5LXU side chains are shown for clarity). The DNA sequences 5'-TAGATACGCA (cyan carbons) and 5'-TATATTCGAA (yellow carbons) are shown as sticks. Right, electrostatic surface representation with electropositive to electronegative surfaces colored from blue to red with helices indicated by arrows. B. Structure-based sequence alignment of representative MYB domains; the three regularly spaced hydrophobic residues characteristic of MYB domains are indicated with a star. Depicted in red are the $\alpha$-helices derived from each corresponding structure. The secondary structure annotation of $\mathrm{LUX}^{\mathrm{MYB}}$ is depicted in blue on top of the aligned sequences ( $\alpha$, alpha helices; TT, strict $\beta$-turn; TTT, strict $\alpha$-turn).

Figure 4. $\mathrm{LUX}^{\mathrm{MYB}}$-DNA interactions. A. Left, overlay of $\mathrm{LUX}^{\mathrm{MYB}}$-DNA structures. Amino acid residues interacting with the DNA are shown as sticks and colored by atom with carbons 
in cyan (5'-TAGATACGCA) or yellow (5'-TATATTCGAA), DNA is shown as a cartoon. Right, simplified schematic from DNAproDB (53) of amino acids important for DNA-binding and base read-out with only direct base interactions shown for clarity. The LBS sequences are depicted without the first overhanging base, major groove interactions are shown in cyan, minor groove interactions in purple, protein helices are in red circles and loop residues are in blue squares. B. Close-up view of Arg146 interactions with DNA colored by atom with carbons in green. The proteins are colored as per A. Hydrogen bonding interactions are shown as dotted lines and distances labelled. Water molecules are shown as red spheres. Arg146 adopts different conformations in the two structures.

Figure 5. Hypocotyl and flowering phenotypes for Col-0, lux-4 and transformed lines. A. Representative hypocotyls from 7-days-old seedlings grown at $22^{\circ}$. B. Hypocotyl length measurements from seedlings grown at $22^{\circ} \mathrm{C}$. One-way anova test was performed (ns, not significant, $* * * *, \mathrm{P}<0.001)$. The error bars represent the median value with interquartile ranges. C. Hypocotyl length measurements from seedlings grown at $27^{\circ} \mathrm{C}$. D. Representative images of plants grown at $22^{\circ} \mathrm{C}$ on soil. Genotypes are indicated. E. Number of rosette leaves at time of bolting from indicated genotypes. Error bars represent the mean with standard deviation. F. PIF4 expression over a 24-hour period for seedlings grown at $22^{\circ} \mathrm{C}$ for the different genotypes. Day and night are indicated as a bar below the graph. Error bars are indicated. 


\section{Figure 1.}

A
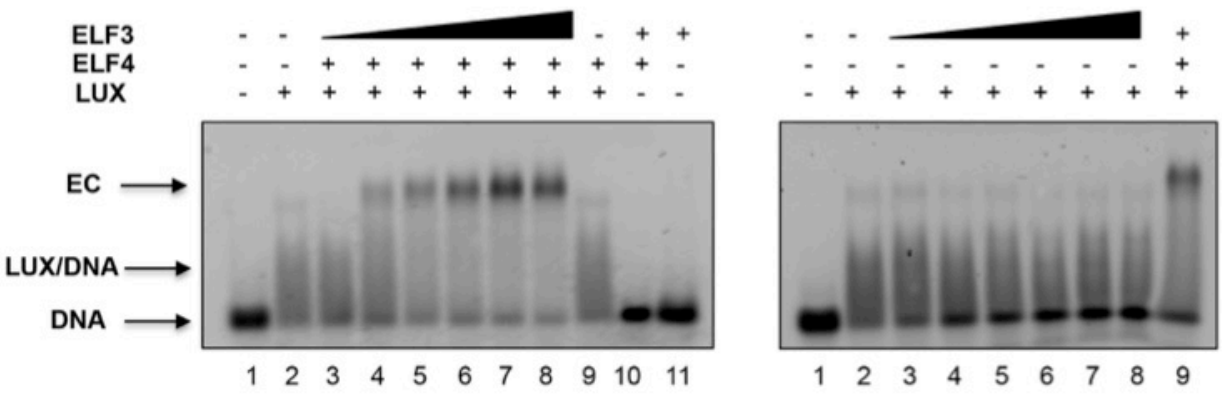

B

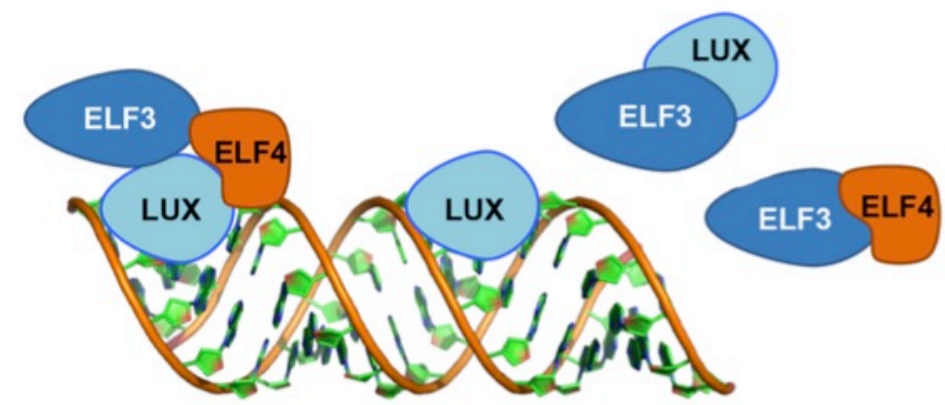




\section{Figure 2.}

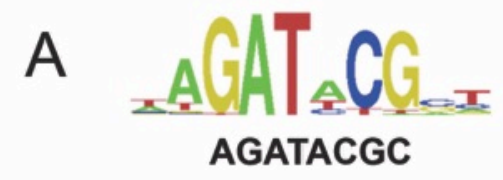

B

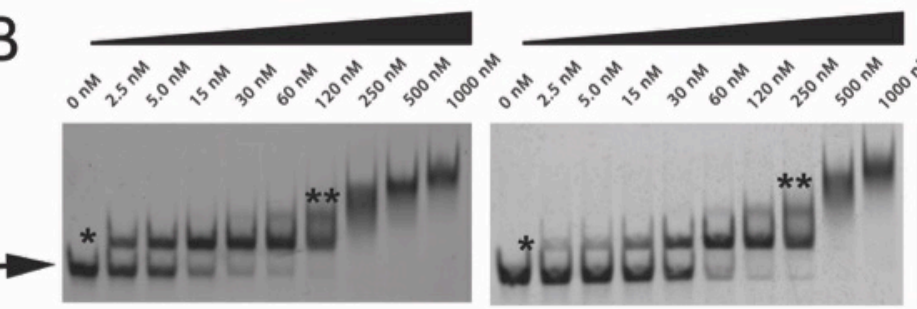

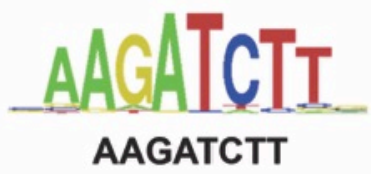

AAGATCTT

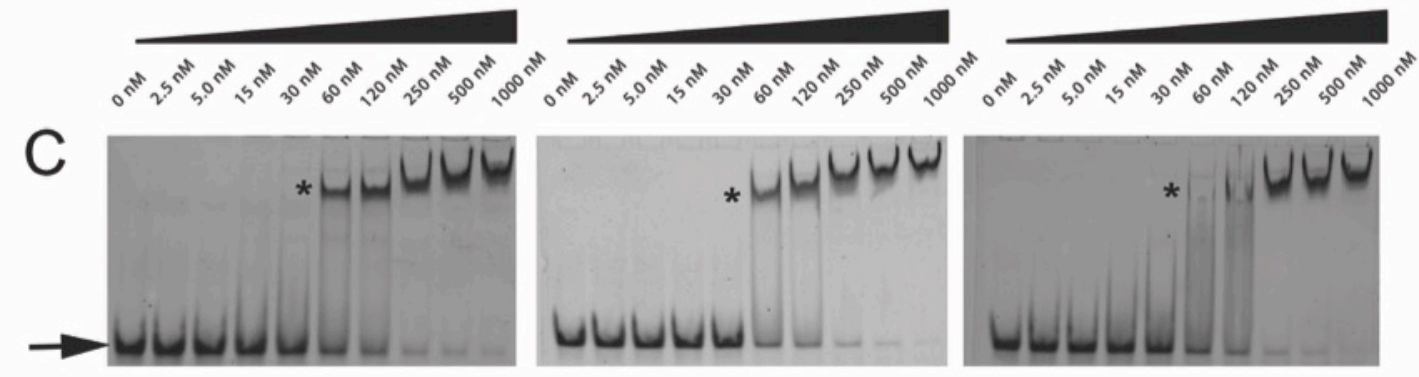




\section{Figure 3.}

A

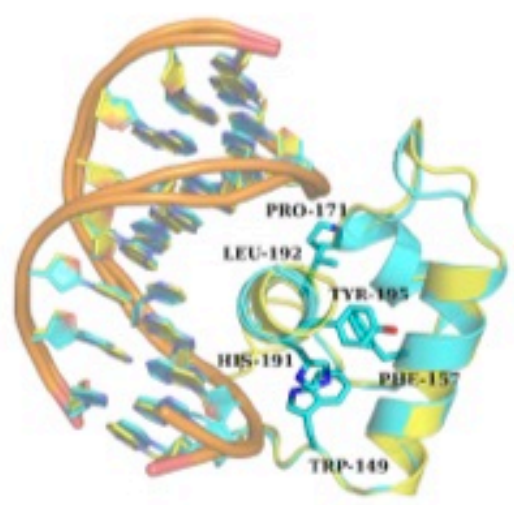

Helix 1

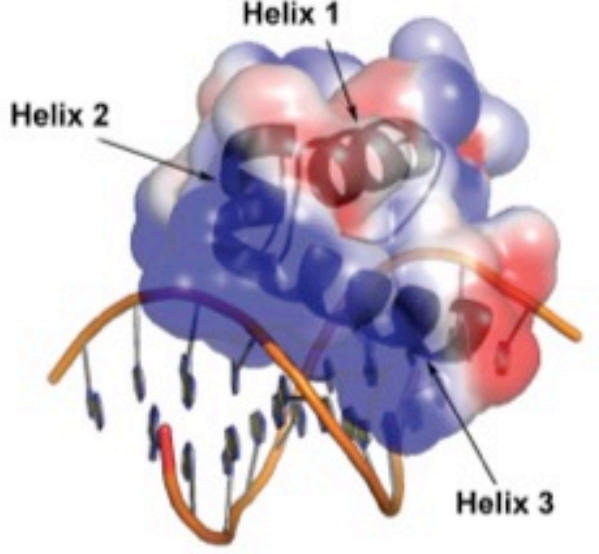

B

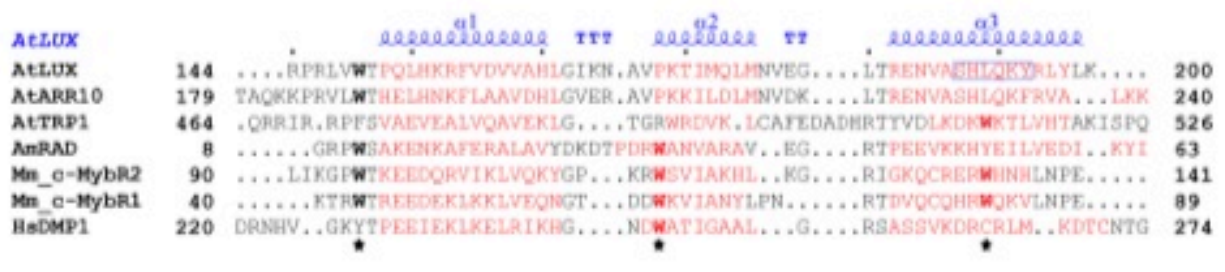




\section{Figure 4.}

A

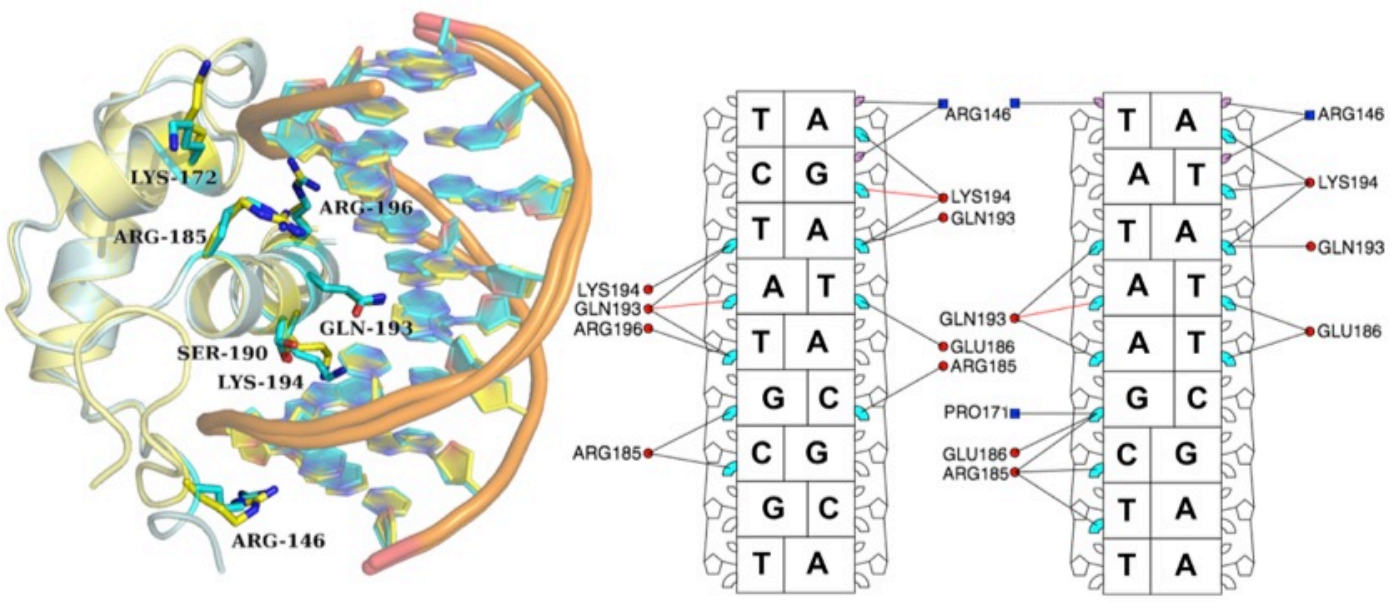

B

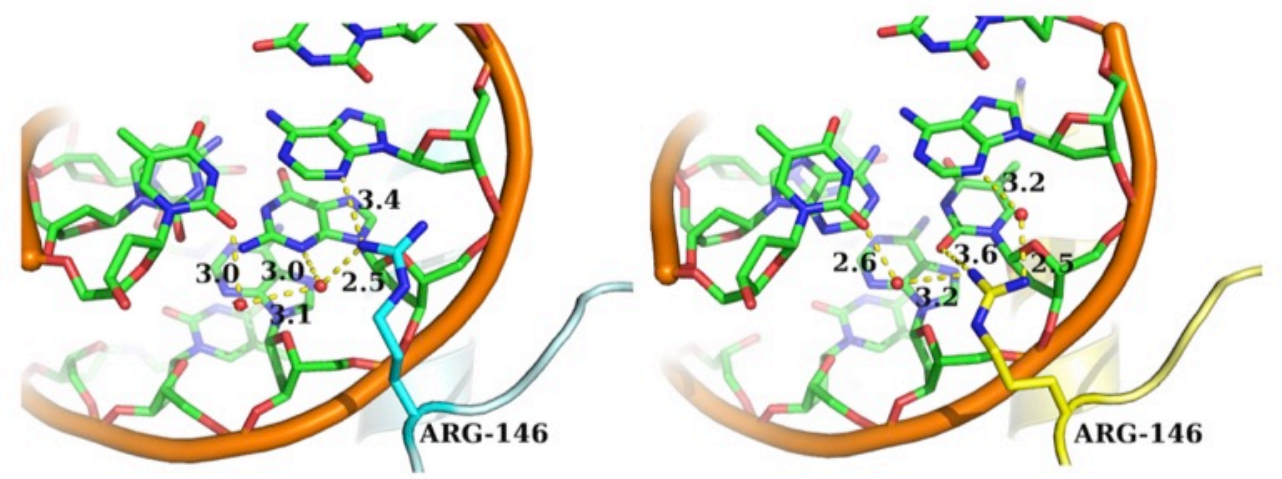




\section{Figure 5.}

A

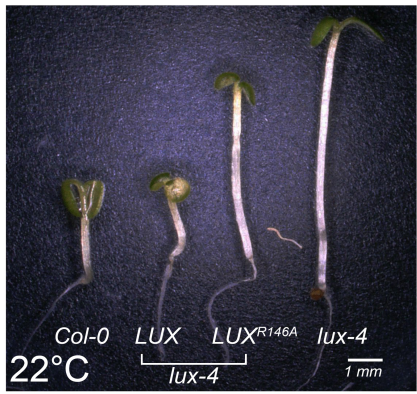

B
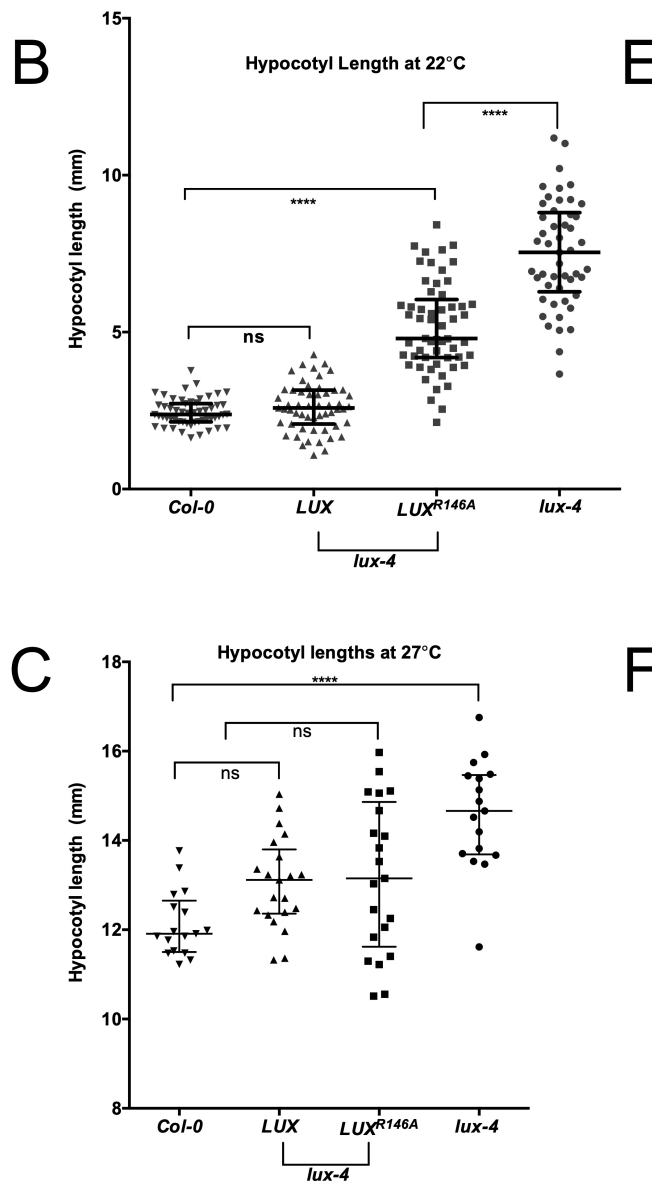

$\mathrm{D}$

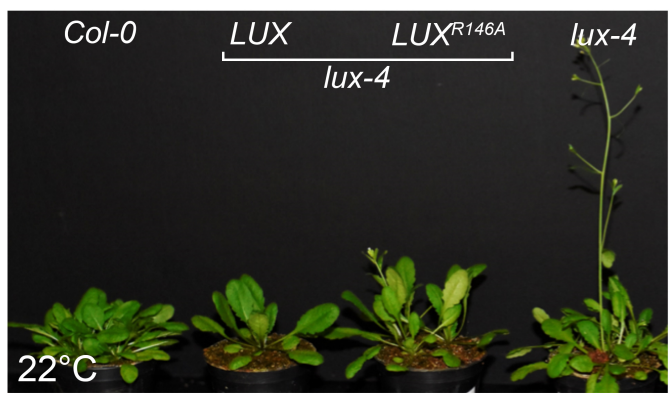

$E$

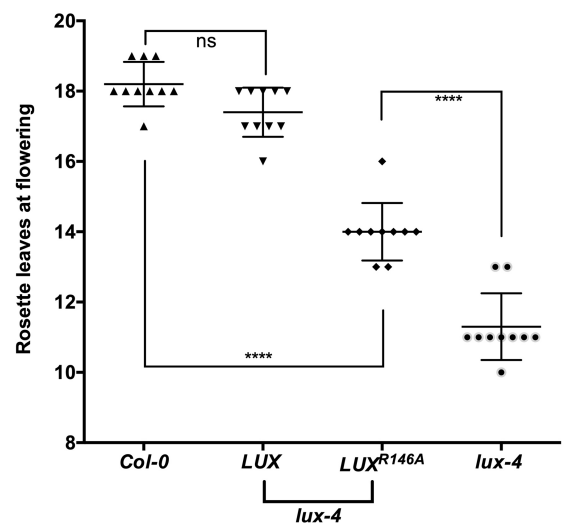

$\mathrm{F}$

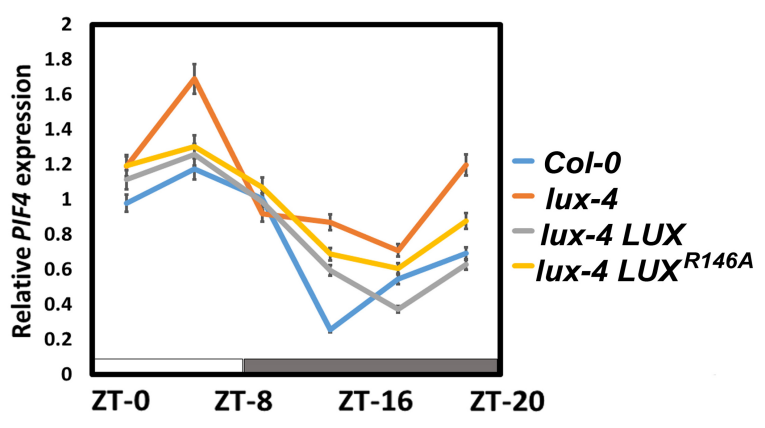




\section{References}

1. Dodd AN, et al. (2005) Plant circadian clocks increase photosynthesis, growth, survival, and competitive advantage. Science 309(5734):630-633.

2. McClung CR (2006) Plant circadian rhythms. The Plant cell 18(4):792-803.

3. Harmer SL (2009) The circadian system in higher plants. Annual review of plant biology 60:357-377.

4. Salome PA, Xie Q, \& McClung CR (2008) Circadian timekeeping during early Arabidopsis development. Plant physiology 147(3):1110-1125.

5. McClung CR (2011) The genetics of plant clocks. Adv Genet 74:105-139.

6. Nagel DH \& Kay SA (2012) Complexity in the wiring and regulation of plant circadian networks. Current biology : CB 22(16):R648-657.

7. Chen ZJ (2013) Genomic and epigenetic insights into the molecular bases of heterosis. Nature reviews. Genetics 14(7):471-482.

8. Hicks KA, Albertson TM, \& Wagner DR (2001) EARLY FLOWERING3 encodes a novel protein that regulates circadian clock function and flowering in Arabidopsis. The Plant cell 13(6):1281-1292.

9. Hazen SP, et al. (2005) LUX ARRHYTHMO encodes a Myb domain protein essential for circadian rhythms. Proceedings of the National Academy of Sciences of the United States of America 102(29):10387-10392.

10. Helfer A, et al. (2011) LUX ARRHYTHMO encodes a nighttime repressor of circadian gene expression in the Arabidopsis core clock. Current biology : $C B$ 21(2):126-133.

11. Herrero E, et al. (2012) EARLY FLOWERING4 recruitment of EARLY FLOWERING3 in the nucleus sustains the Arabidopsis circadian clock. The Plant cell 24(2):428-443.

12. Nusinow DA, et al. (2011) The ELF4-ELF3-LUX complex links the circadian clock to diurnal control of hypocotyl growth. Nature 475(7356):398-402.

13. Chow BY, Helfer A, Nusinow DA, \& Kay SA (2012) ELF3 recruitment to the PRR9 promoter requires other Evening Complex members in the Arabidopsis circadian clock. Plant signaling \& behavior 7(2):170-173.

14. Mizuno T, et al. (2014) Ambient temperature signal feeds into the circadian clock transcriptional circuitry through the EC night-time repressor in Arabidopsis thaliana. Plant \& cell physiology 55(5):958-976.

15. Ezer D, et al. (2017) The evening complex coordinates environmental and endogenous signals in Arabidopsis. Nat Plants 3:17087.

16. Onai K \& Ishiura M (2005) PHYTOCLOCK 1 encoding a novel GARP protein essential for the Arabidopsis circadian clock. Genes to cells : devoted to molecular \& cellular mechanisms 10(10):963-972.

17. Doyle MR, et al. (2002) The ELF4 gene controls circadian rhythms and flowering time in Arabidopsis thaliana. Nature 419(6902):74-77.

18. Hicks KA, et al. (1996) Conditional circadian dysfunction of the Arabidopsis early-flowering 3 mutant. Science 274(5288):790-792.

19. Nozue K, et al. (2007) Rhythmic growth explained by coincidence between internal and external cues. Nature 448(7151):358-361.

20. Box MS, et al. (2015) ELF3 controls thermoresponsive growth in Arabidopsis. Current biology : CB 25(2):194-199.

21. Gawronski P, et al. (2014) A distorted circadian clock causes early flowering and temperature-dependent variation in spike development in the Eps-3Am mutant of einkorn wheat. Genetics 196(4):1253-1261. 
22. Undurraga SF, et al. (2012) Background-dependent effects of polyglutamine variation in the Arabidopsis thaliana gene ELF3. Proceedings of the National Academy of Sciences of the United States of America 109(47):19363-19367.

23. Raschke A, et al. (2015) Natural variants of ELF3 affect thermomorphogenesis by transcriptionally modulating PIF4-dependent auxin response genes. BMC Plant Biol 15:197.

24. Castillon A, Shen H, \& Huq E (2007) Phytochrome Interacting Factors: central players in phytochrome-mediated light signaling networks. Trends Plant Sci 12(11):514-521.

25. Leivar P \& Quail PH (2011) PIFs: pivotal components in a cellular signaling hub. Trends Plant Sci 16(1):19-28.

26. Kumar SV, et al. (2012) Transcription factor PIF4 controls the thermosensory activation of flowering. Nature 484(7393):242-245.

27. Lucyshyn D \& Wigge PA (2009) Plant development: PIF4 integrates diverse environmental signals. Current biology : CB 19(6):R265-266.

28. Hornitschek P, Lorrain S, Zoete V, Michielin O, \& Fankhauser C (2009) Inhibition of the shade avoidance response by formation of non-DNA binding bHLH heterodimers. The EMBO journal 28(24):3893-3902.

29. Huang H \& Nusinow DA (2016) Into the Evening: Complex Interactions in the Arabidopsis Circadian Clock. Trends Genet 32(10):674-686.

30. Franco-Zorrilla JM, et al. (2014) DNA-binding specificities of plant transcription factors and their potential to define target genes. Proceedings of the National Academy of Sciences of the United States of America 111(6):2367-2372.

31. Godoy $\mathrm{M}$, et al. (2011) Improved protein-binding microarrays for the identification of DNA-binding specificities of transcription factors. The Plant journal : for cell and molecular biology 66(4):700-711.

32. Kanei-Ishii C, et al. (1990) The tryptophan cluster: a hypothetical structure of the DNA-binding domain of the myb protooncogene product. The Journal of biological chemistry 265(32):19990-19995.

33. Pokhilko A, et al. (2012) The clock gene circuit in Arabidopsis includes a repressilator with additional feedback loops. Mol Syst Biol 8:574.

34. Koini MA, et al. (2009) High temperature-mediated adaptations in plant architecture require the bHLH transcription factor PIF4. Current biology : $C B$ 19(5):408-413.

35. Gangappa SN, Berriri S, \& Kumar SV (2017) PIF4 Coordinates Thermosensory Growth and Immunity in Arabidopsis. Current biology : CB 27(2):243-249.

36. Hazen SP, et al. (2005) Rapid array mapping of circadian clock and developmental mutations in Arabidopsis. Plant physiology 138(2):990-997.

37. Zagotta MT, Shannon, S., Jacobs, C., Meeks-Wagner, D.R. (1992) Early-flowering mutants of A. thaliana. Austr. J. Plant Physiol. 19:411-418.

38. Zagotta MT, et al. (1996) The Arabidopsis ELF3 gene regulates vegetative photomorphogenesis and the photoperiodic induction of flowering. The Plant journal : for cell and molecular biology 10(4):691-702.

39. Nieto C, Lopez-Salmeron V, Daviere JM, \& Prat S (2015) ELF3-PIF4 interaction regulates plant growth independently of the Evening Complex. Current biology: CB 25(2):187-193.

40. Burglin TR \& Affolter M (2016) Homeodomain proteins: an update. Chromosoma 125(3):497-521. 
41. Kappel S, Melzer R, Rumpler F, Gafert C, \& Theissen G (2018) The floral homeotic protein SEPALLATA3 recognizes target DNA sequences by shape readout involving a conserved arginine residue in the MADS-domain. The Plant journal : for cell and molecular biology 95(2):341-357.

42. Mathelier A, et al. (2016) DNA Shape Features Improve Transcription Factor Binding Site Predictions In Vivo. Cell Syst 3(3):278-286 e274.

43. Desai TA, Rodionov DA, Gelfand MS, Alm EJ, \& Rao CV (2009) Engineering transcription factors with novel DNA-binding specificity using comparative genomics. Nucleic acids research 37(8):2493-2503.

44. Dougherty MJ \& Arnold FH (2009) Directed evolution: new parts and optimized function. Curr Opin Biotechnol 20(4):486-491.

45. Xiong AS, et al. (2013) Expression and function of a modified AP2/ERF transcription factor from Brassica napus enhances cold tolerance in transgenic Arabidopsis. Mol Biotechnol 53(2):198-206.

46. Hart DJ \& Tarendeau F (2006) Combinatorial library approaches for improving soluble protein expression in Escherichia coli. Acta crystallographica. Section D, Biological crystallography 62(Pt 1):19-26.

47. Guilligay D, et al. (2008) The structural basis for cap binding by influenza virus polymerase subunit PB2. Nat Struct Mol Biol 15(5):500-506.

48. Doublie S (2007) Production of selenomethionyl proteins in prokaryotic and eukaryotic expression systems. Methods in molecular biology 363:91-108.

49. Vijayachandran LS, et al. (2011) Robots, pipelines, polyproteins: enabling multiprotein expression in prokaryotic and eukaryotic cells. J Struct Biol 175(2):198-208.

50. Silva CS, Lai X, Nanao M, \& Zubieta C (2016) The Myb domain of LUX ARRHYTHMO in complex with DNA: expression, purification and crystallization. Acta Crystallogr F Struct Biol Commun 72(Pt 5):356-361.

51. Pei J, Kim BH, \& Grishin NV (2008) PROMALS3D: a tool for multiple protein sequence and structure alignments. Nucleic acids research 36(7):2295-2300.

52. Zhang Y \& Skolnick J (2005) TM-align: a protein structure alignment algorithm based on the TM-score. Nucleic acids research 33(7):2302-2309.

53. Sagendorf JM, Berman HM, \& Rohs R (2017) DNAproDB: an interactive tool for structural analysis of DNA-protein complexes. Nucleic acids research 45(W1):W89-W97.

54. Bieniossek C, Richmond TJ, \& Berger I (2008) MultiBac: multigene baculovirusbased eukaryotic protein complex production. Curr Protoc Protein Sci Chapter 5:Unit 520.

55. Trowitzsch S, Bieniossek C, Nie Y, Garzoni F, \& Berger I (2010) New baculovirus expression tools for recombinant protein complex production. J Struct Biol 172(1):45-54.

56. Incardona MF, et al. (2009) EDNA: a framework for plugin-based applications applied to X-ray experiment online data analysis. Journal of synchrotron radiation 16(Pt 6):872-879.

57. Kabsch W (2010) Xds. Acta crystallographica. Section D, Biological crystallography 66(Pt 2):125-132.

58. Sheldrick GM (2008) A short history of SHELX. Acta crystallographica. Section A, Foundations of crystallography 64(Pt 1):112-122. 
59. Bricogne G. BE, Brandl M., Flensburg C., Keller P., Paciorek W., Roversi P., Sharff A., Smart O.S., Vonrhein C., Womack T.O. (2011) BUSTER version 2.10.0. (Global Phasing Ltd., Cambridge, United Kingdom).

57. Bensmihen, S., To, A., Lambert, G., Kroj, T., Giraudat, J., \& Parcy, F. (2004). Analysis of an activated ABI5 allele using a new selection method for transgenic Arabidopsis seeds. FEBS letters, 561(1-3), 127-131.

58. Fraley, R. T., Rogers, S. G., Horsch, R. B., Eichholtz, D. A., Flick, J. S., Fink, C. L., ... \& Sanders, P. R. (1985). The SEV system: a new disarmed Ti plasmid vector system for plant transformation. Nature Biotechnology, 3(7), 629. 


\section{Supplemental Information}

SI Table 1. Data collection and refinement statistics

\begin{tabular}{|c|c|c|}
\hline & $\begin{array}{l}\text { LUX } \\
\text { 5'-TAGATACGCA }\end{array}$ & $\begin{array}{l}\text { LUX }{ }^{\mathrm{MYB}} \\
\text { 5'-TATATTCGAA }\end{array}$ \\
\hline \multicolumn{3}{|l|}{ Data collection } \\
\hline Space group & $\mathrm{P} 2_{1}$ & $\mathrm{P} 2_{1}$ \\
\hline \multicolumn{3}{|l|}{ Cell dimensions } \\
\hline$a, b, c(\AA)$ & $42.16,32.83,53.76$ & $32.76,51.79,35.99$ \\
\hline$\alpha, \beta, \gamma\left({ }^{\circ}\right)$ & $90,98.6,90$ & $90,110.55,90$ \\
\hline Resolution $(\AA)$ & $42 .-2.14(2.22-2.14)^{*}$ & $30.67-1.66(1.72-1.66)$ \\
\hline$R_{\text {sym }}$ or $R_{\text {merge }}(\%)$ & $6.1(60)$ & $3.7(63.7)$ \\
\hline$I / \sigma I$ & $12.5(2.0)$ & $8.1(1.0)$ \\
\hline Completeness (\%) & $91(57)$ & $94.2(81.6)$ \\
\hline Redundancy & $2.8(1.7)$ & $2.5(2.0)$ \\
\hline \multicolumn{3}{|l|}{ Refinement } \\
\hline Resolution $(\AA)$ & $41.7-2.14$ & $30.67-1.9$ \\
\hline No. reflections & 7572 & 7556 \\
\hline$R_{\text {work }} / R_{\text {free }}$ & $19.5 / 23.2$ & $19.2 / 23.9$ \\
\hline No. atoms & 975 & 1107 \\
\hline Protein & 491 & 551 \\
\hline DNA & 409 & 403 \\
\hline Water & 75 & 137 \\
\hline Other ligands & - & 16 \\
\hline \multicolumn{3}{|l|}{$B$-factors } \\
\hline Protein & 56 & 25 \\
\hline DNA & 58 & 24 \\
\hline Water & 56 & 30 \\
\hline Other ligands & - & 47 \\
\hline \multicolumn{3}{|l|}{ R.m.s. deviations } \\
\hline Bond lengths $(\AA)$ & 0.01 & 0.008 \\
\hline Bond angles $\left({ }^{\circ}\right)$ & 1.06 & 1.009 \\
\hline
\end{tabular}


SI Table 2. Primers used for design of plant expression vector and qRT-PCR (F=forward primer, $\mathrm{R}=$ reverse primer)

\begin{tabular}{|l|l|l|}
\hline Primer Name & Sequence & $\begin{array}{l}\text { Amplicon } \\
\text { length }\end{array}$ \\
\hline $\begin{array}{l}L U X \\
\text { Promoter }(\mathrm{F})\end{array}$ & GCTAAGCTTGCATGCCTGCACGTTTCGTCAGTTTGTGAAG & $780 \mathrm{bp}$ \\
\hline $\begin{array}{l}L U X \\
\text { Promoter } \\
\text { Reverse }(\mathrm{R})\end{array}$ & ATCGTCTTTGTAGTCCATTTCAAACTCTCTAATTTCTCG & \\
\hline $\begin{array}{l}\text { LUX } \mathrm{cDNA} \\
(\mathrm{F})\end{array}$ & $\begin{array}{l}\text { AGAGTTTGAAATGGACTACAAAGACGATGACGACAAGATGGG } \\
\text { AGAGGAAGTACAAATG }\end{array}$ & $1009 \mathrm{bp}$ \\
$\begin{array}{l}\text { RU } \mathrm{cDNA} \\
\text { PP } 2 A \text { qPCR } \\
(\mathrm{F})\end{array}$ & TCTGCAGGTCGACGGATCCTTTAATTCTCATTTGCGCTTC & \\
\hline $\begin{array}{l}P P 2 A \text { qPCR } \\
(\mathrm{R})\end{array}$ & GCTTGGTCGACTATCGGAATGAGAG & $173 \mathrm{bp}$ \\
\hline $\begin{array}{l}P I F 4 \text { qPCR } \\
(\mathrm{F})\end{array}$ & GCCAAAACCCGGTACAAAACCA & $125 \mathrm{bp}$ \\
\hline $\begin{array}{l}P I F 4 \text { qPCR } \\
(\mathrm{R})\end{array}$ & CGCCGGTGAACTAAATCTCAACATC & \\
\hline
\end{tabular}

SI Figure 1. $L U X^{\mathrm{FL}}$ and $L U X^{\mathrm{MYB}} 3$ top-scoring motifs and position weight matrices

\section{LUX $X^{\mathrm{FL}} 3$ top-scoring motifs}

$\# 1 \quad$ AGATACGC E $=0.492063974$

A: $\quad \begin{array}{llllll}0.35142453 & 0.804055821 & 0.003718987 & 0.986953742 & 0.004747935\end{array}$

$\begin{array}{llllll}0.577262184 & 0.002384451 & 0.018599922 & 0.129789053 & 0.153888619\end{array}$

C: $\quad \begin{array}{lllllll}0.112736188 & 0.026365574 & 0.001199577 & 0.001496092 & 0.00372122\end{array}$

$\begin{array}{llllll}0.150304531 & 0.923788281 & 0.00885655 & 0.439817615 & 0.160123166\end{array}$

G: $\quad \begin{array}{llllll}0.09515845 & 0.049256169 & 0.978072785 & 0.005820791 & 0.001344828\end{array}$

$\begin{array}{llllll}0.001842705 & 0.002468208 & 0.93355721 & 0.357258447 & 0.08021055\end{array}$

T: $\quad \begin{array}{llllll}0.440680832 & 0.120322436 & 0.017008651 & 0.005729376 & 0.990186017\end{array}$

$\begin{array}{llllll}0.27059058 & 0.07135906 & 0.038986318 & 0.073134885 & 0.605777666\end{array}$

\#2 AGATACGG E=0.491233233

A: $\quad \begin{array}{llllll}0.35142453 & 0.741615845 & 0.003565014 & 0.984991726 & 0.004690722\end{array}$

$\begin{array}{llllll}0.521252234 & 0.002185495 & 0.008666301 & 0.129789053 & 0.153888619\end{array}$

C: $\quad \begin{array}{llllll}0.112736188 & 0.05385204 & 0.002117419 & 0.002515741 & 0.004490424\end{array}$

$\begin{array}{llllll}0.058281493 & 0.895266117 & 0.03003779 & 0.439817615 & 0.160123166\end{array}$

G: $\quad \begin{array}{llllll}0.09515845 & 0.084747485 & 0.975778873 & 0.006329294 & 0.001968417\end{array}$

$\begin{array}{llllll}0.002887713 & 0.002914035 & 0.934645009 & 0.357258447 & 0.08021055\end{array}$ 
T: $\quad \begin{array}{llllll}0.440680832 & 0.119784631 & 0.018538693 & 0.006163239 & 0.988850437\end{array}$

$\begin{array}{llllll}0.41757856 & 0.099634354 & 0.0266509 & 0.073134885 & 0.605777666\end{array}$

\#3 AAGATCTT E $=0.490881694$

A: $\quad \begin{array}{llllll}0.168228312 & 0.859911075 & 0.938185345 & 0.052783437 & 0.981167559\end{array}$

$\begin{array}{llllll}0.00290063 & 0.041542151 & 0.009740091 & 0.026766284 & 0.168251311\end{array}$

C: $\quad \begin{array}{llllll}0.355473075 & 0.048558299 & 0.006938662 & 0.000496514 & 0.002297965\end{array}$

$\begin{array}{llllll}0.013633845 & 0.905177898 & 0.045135902 & 0.064764343 & 0.296884129\end{array}$

G: $\quad \begin{array}{llllll}0.339219521 & 0.064764343 & 0.045135902 & 0.905177898 & 0.013633845\end{array}$

$\begin{array}{llllll}0.002297965 & 0.000496514 & 0.006938662 & 0.048558299 & 0.412530557\end{array}$

$\begin{array}{lllllll}\mathrm{T}: & 0.137079093 & 0.026766284 & 0.009740091 & 0.041542151 & 0.00290063\end{array}$

$\begin{array}{llllll}0.981167559 & 0.052783437 & 0.938185345 & 0.859911075 & 0.122334004\end{array}$

\section{LUX $\mathbf{X Y B}^{\mathrm{M}}$ top-scoring motifs}

\#1 CGGATCCG E=0.454140218

A: $\quad \begin{array}{llllll}0.261061917 & 0.245890548 & 0.228057278 & 0.157759851 & 0.865119077\end{array}$ $\begin{array}{llllll}0.077760423 & 0.213407473 & 0.051924772 & 0.195908809 & 0.129531752\end{array}$

C: $\quad \begin{array}{llllll}0.258747752 & 0.493014035 & 0.12560441 & 0.035664191 & 0.016117529\end{array}$ $\begin{array}{llllll}0.041002971 & 0.593168485 & 0.59441354 & 0.065186608 & 0.41565548\end{array}$

G: $\quad \begin{array}{llllll}0.244535034 & 0.065186608 & 0.59441354 & 0.593168485 & 0.041002971\end{array}$ $\begin{array}{llllll}0.016117529 & 0.035664191 & 0.12560441 & 0.493014035 & 0.252844114\end{array}$

T: $\quad \begin{array}{llllll}0.235655296 & 0.195908809 & 0.051924772 & 0.213407473 & 0.077760423\end{array}$ $\begin{array}{llllll}0.865119077 & 0.157759851 & 0.228057278 & 0.245890548 & 0.201968654\end{array}$

\#2 GAATATTC $\mathrm{E}=0.451898506$

A: $\quad \begin{array}{llllll}0.25591826 & 0.132822385 & 0.733549561 & 0.88813316 & 0.008075874\end{array}$ $\begin{array}{llllll}0.851976892 & 0.088170535 & 0.107576516 & 0.104549885 & 0.110462435\end{array}$

C: $\quad \begin{array}{lllllll}0.263883236 & 0.080074963 & 0.039747475 & 0.013475127 & 0.026180465\end{array}$ $\begin{array}{llllll}0.113766769 & 0.010221178 & 0.119126448 & 0.682552766 & 0.187751258\end{array}$

G: $\quad \begin{array}{llllll}0.212055326 & 0.682552766 & 0.119126448 & 0.010221178 & 0.113766769\end{array}$ $\begin{array}{lllllll}0.026180465 & 0.013475127 & 0.039747475 & 0.080074963 & 0.362317244\end{array}$

T: $\quad \begin{array}{lllllll}0.268143178 & 0.104549885 & 0.107576516 & 0.088170535 & 0.851976892\end{array}$ $\begin{array}{llllll}0.008075874 & 0.88813316 & 0.733549561 & 0.132822385 & 0.339469063\end{array}$

\#3 GCGGATCC E=0.436975783

A: $\quad \begin{array}{llllll}0.312324487 & 0.201968654 & 0.133133957 & 0.097987457 & 0.131636637\end{array}$ 


\section{$\begin{array}{llllll}0.915211071 & 0.080058604 & 0.090823789 & 0.125729895 & 0.195908809\end{array}$}
C: $\quad 0.123485658$
0.252844114
0.689021647
$0.052431447 \quad 0.036141879$
0.0080192
0.05685898
0.688792149
0.545550076
0.065186608

$\begin{array}{llllll}\text { G: } & 0.25667656 & 0.41565548 & 0.067701641 & 0.807521578 & 0.658089186 \\ & 0.019754659 & 0.016268336 & 0.07105598 & 0.129182967 & 0.493014035\end{array}$

$\mathrm{T}: \quad 0.307513294$

0.129531752

0.110142755

0.042059517

0.174132299

0.05701507

0.846814079

0.149328083

0.199537062

0.245890548

SI Figure 2. DNA sequences used for plasmid constructions for transformation in plants.

pLUX:FLAG:LUX (the FLAG-tag is in bold and underlined)

cgtttcgtcagtttgtgaagttggggcatcgaacccgtgacgttgaagaagctaaacagagtaactaaacctctctgagcctttcc acaataattattttcattttcttaaaagttaggtgccagccaatctgtgccgttagattgatctttatatgcttctataaatatctaaa acaacaatccaacggtggaaagatcacattgcgtgtcagtactgtagatactcatcaccgaatctttctcctcttttcactctccag ctggccgaacccaccggttttgcccactttctctctaggcccgcaaacacaacttgctaagtcggtagtaatttactgaaaaaccc tcacaaatagctgacttggctcttttcactccacgtggctccatcttacgtgcctagtttggtaatttcaatttcaatcacctagatcg taactattgatacataatgtgaactgatgacgtgttgaaaagagattggttaggtcggtttgaaaagatatttagaagatctaaa atatctagctaactcgtccacgttggaattaaaatattgcgctttttcctggaaaagaaaaatataaaacaagtgataatcttctct ttttcgaaattgtttcacttctgaaaaaaaaaaaaaaaaaattgtttgctcatcatcttcacaaaccaaacttctcttcttctccga tctcagatttgaatttttatcgattttgagcttcgaagagctcaatctctaactgaatttcgagaaattagagagtttgaaatggac tacaaagacgatgacgacaagatgggagaggaagtacaaatgagcgattacgatgtttccggcgacggagatagggtttct gaatgggagatgggattaccaagcgacgaagatctagcatctctttcttactctctgattccaccgaatttggcgatggcgtttag tatcacaccggagagaagccgtacgattcaggatgtgaatcgtgcatcggagacgacgctctcgtcgctacgtggtggatcttc aggtccaaatacctcgtcgtcgaataataacgtggaggaggaagatcgagttggatctagcagtcctggatcggattcgaagaa gcaaaagacatcaaacggtgatggagatgacggtggcggtgtggatccggattcggcgatggcggcggaagaaggagattca ggaactgaagatctatctgggaaaacacttaaacgaccgcgtttagtgtggacaccgcagctacacaagagattcgttgacgtt gtagctcacttagggatcaaaaacgctgttccgaagacgattatgcagctgatgaacgttgaaggattaactcgtgagaacgtt gcgtctcatcttcaaaagtataggctttacctcaaaaggatgcagggattgactaatgaaggtccctctgcttcggataagctctt ctcttcaacacctgttcctccacagagcttccaagatatcggtggcggtggcggtagcagcggtaatgttggagtgccgattccg ggggcgtatggaacgcaacagatgatgcagatgccagtttatgcacatcatatgggtatgcaaggatatcatcatcaaaatcat aatcatgatccttatcatcagaatcatcgtcatcatcatggagctggtggaaatggtgcgtttgagtcaaatccttatatgatgca gcagaataagtttggatccatggcttcttatccttctgttggaggtggaagcgcaaatgagaattaa

pLUX:FLAG:LUX ${ }^{\mathrm{R} 146 \mathrm{~A}}$ (the FLAG-tag is in bold and underlined)

cgtttcgtcagtttgtgaagttggggcatcgaacccgtgacgttgaagaagctaaacagagtaactaaacctctctgagcctttcc acaataattattttcattttcttaaaagttaggtgccagccaatctgtgccgttagattgatctttatatgcttctataaatatctaaa acaacaatccaacggtggaaagatcacattgcgtgtcagtactgtagatactcatcaccgaatctttctcctctttcactctccag ctggccgaacccaccggttttgcccactttctctctaggcccgcaaacacaacttgctaagtcggtagtaatttactgaaaaaccc tcacaaatagctgacttggctcttttcactccacgtggctccatcttacgtgcctagtttggtaatttcaatttcaatcacctagatcg taactattgatacataatgtgaactgatgacgtgttgaaaagagattggttaggtcggtttgaaaagatatttagaagatctaaa atatctagctaactcgtccacgttggaattaaaatattgcgctttttcctggaaaagaaaaatataaaacaagtgataatcttctct ttttcgaaattgtttcacttctgaaaaaaaaaaaaaaaaaattgtttgctcatcatcttcacaaaccaaacttctcttcttctccga 
tctcagatttgaatttttatcgattttgagcttcgaagagctcaatctctaactgaatttcgagaaattagagagtttgaaatggac tacaaagacgatgacgacaagatgggagaggaagtacaaatgagcgattacgatgtttccggcgacggagatagggtttct gaatgggagatgggattaccaagcgacgaagatctagcatctctttcttactctctgattccaccgaatttggcgatggcgtttag tatcacaccggagagaagccgtacgattcaggatgtgaatcgtgcatcggagacgacgctctcgtcgctacgtggtggatcttc aggtccaaatacctcgtcgtcgaataataacgtggaggaggaagatcgagttggatctagcagtcctggatcggattcgaagaa gcaaaagacatcaaacggtgatggagatgacggtggcggtgtggatccggattcggcgatggcggcggaagaaggagattca ggaactgaagatctatctgggaaaacacttaaacgaccggctttagtgtggacaccgcagctacacaagagattcgttgacgtt gtagctcacttagggatcaaaaacgctgttccgaagacgattatgcagctgatgaacgttgaaggattaactcgtgagaacgtt gcgtctcatcttcaaaagtataggctttacctcaaaaggatgcagggattgactaatgaaggtccctctgcttcggataagctctt ctcttcaacacctgttcctccacagagcttccaagatatcggtggcggtggcggtagcagcggtaatgttggagtgccgattccg ggggcgtatggaacgcaacagatgatgcagatgccagtttatgcacatcatatgggtatgcaaggatatcatcatcaaaatcat aatcatgatccttatcatcagaatcatcgtcatcatcatggagctggtggaaatggtgcgtttgagtcaaatccttatatgatgca gcagaataagtttggatccatggcttcttatccttctgttggaggtggaagcgcaaatgagaattaa

\section{$\underline{\text { SI Materials and Methods }}$}

\section{Protein binding microarrays}

Translational fusions of LUX (LUX FL; TAIR At3g46640.1) and LUX ${ }^{\mathrm{MYB}}$ (amino acid residues 139-200) to Maltose Binding Protein were obtained by cloning their corresponding cDNAs into the pETM41 vector (EMBL) using restriction sites NcoI and NotI. Clones were sequence verified and the plasmids introduced into Escherichia coli BL21. Recombinant proteins were expressed as described (30,31). DNA-binding specificities were determined using protein binding microarrays (PBM11), incubated with soluble protein extracts obtained from $25 \mathrm{~mL}$ induced E. coli cultures. Incubation of protein extracts and antibodies, washing, scanning, quantification and analysis were performed as described (30, 31). The top 3 highest scoring motifs are given in SI Figure 1.

\section{Protein expression}

The full-length LUX was cloned into the expression vector pESPRIT002(46, 47) using the AatII and NotI restriction sites. A second construct LUX ${ }^{\mathrm{MYB}}$ (amino acid residues 139200) was generated following the same strategy. Both constructs contained a TEV protease cleavable N-terminal $6 \mathrm{x}-\mathrm{His}$ tag. $\mathrm{LUX}^{\mathrm{FL}}$ and $\mathrm{LUX}^{\mathrm{MYB}}$ constructs were overproduced in Escherichia coli (E.coli) Rosetta2 (DE3) pLysS cells. Cells were grown at $37^{\circ} \mathrm{C}$ in LuriaBertani (LB) culture medium supplemented with chloramphenicol $(37 \mathrm{mg} / \mathrm{mL})$ and kanamycin $(50 \mathrm{mg} / \mathrm{mL})$, until an $\mathrm{OD}_{600}$ of $0.7-0.8$. The temperature was then reduced to $20^{\circ} \mathrm{C}$ and protein expression induced by addition of $1 \mathrm{mM}$ isopropyl- $\beta$-D-thiogalactopyranoside (IPTG); expression was continued overnight $(\sim 16 \mathrm{~h})$ and the cells were harvested by centrifugation for $30 \mathrm{~min}$. at $6000 \mathrm{rpm}$ at $4^{\circ} \mathrm{C}$.

Seleno-methionine (SeMet) derived $\mathrm{LUX}^{\mathrm{MYB}}$ protein was produced according to standard protocols (48). Briefly, SeMet LUX ${ }^{\mathrm{MYB}}$ was produced in M9 minimal medium using a non-auxotrophic strain (Rosetta2 (DE3) pLysS cells). Overnight grown LB precultures were spun down, washed with M9 medium and used to inoculate M9 cultures supplemented with chloramphenicol $(37 \mathrm{mg} / \mathrm{mL})$, kanamycin $(50 \mathrm{mg} / \mathrm{mL}), \mathrm{MgSO}_{4}(2 \mathrm{mM})$, glucose $(0.4 \% \mathrm{w} / \mathrm{v})$ and $\mathrm{MgCl}_{2}(0.1 \mathrm{mM})$. Cells were grown at $37^{\circ} \mathrm{C}$ until an $\mathrm{OD}_{600}$ of 1.2 was reached. Amino acids $(100 \mathrm{mg} / \mathrm{L}$ lysine, threonine and phenylalanine; $50 \mathrm{mg} / \mathrm{L}$ leucine, valine, isoleucine and L-seleno-methionine) were added and the temperature reduced to $20^{\circ} \mathrm{C}$. After 15 minutes, 0.5 mM IPTG was added to induce protein expression and the culture grown overnight. Cells were harvested as for the native protein.

ELF4 full-length coding sequence (TAIR At2g40080.1) was cloned into the expression vector pESPRIT002 $(46,47)$ following the same strategy as for $\mathrm{LUX}^{\mathrm{FL}}$. The 
resulting construct, containing a TEV cleavable N-terminal 6x-His tag, was overproduced in Escherichia coli (E.coli) BL21 CodonPlus RIL cells under the same conditions as LUX ${ }^{\mathrm{FL}}$.

Full-length ELF3 (TAIR At2g25930.1) was cloned into the pACEBac1(49) vector via SalI and NotI restriction sites and inserting a TEV protease cleavable $6 \mathrm{x}$-His sequence at both $\mathrm{N}$ - and C-terminal ends of the gene. ELF3 protein was produced in $S f 21$ insect cells (Invitrogen) using the baculovirus expression system. Briefly, the generated construct was transformed into chemically competent DH10 EmBacY cells (harbouring the baculoviral EmBacY genome) $(54,55)$. Positive clones were identified by blue/white screening in the presence of IPTG and BluoGal and used for downstream bacmid isolation. Sf21 insect cells were transfected at a density of $0.3 \times 10^{6}$ cells $/ \mathrm{mL}$ in a 6 -well plate format. Primary baculovirus stock $\left(\mathrm{V}_{0}\right)$ was harvested $60 \mathrm{~h}$ after transfection and used for infecting $25 \mathrm{~mL}$ new Sf21 cell cultures yielding $\mathrm{V}_{1}$ stock. $\mathrm{V}_{1}$ baculovirus stock was collected $48 \mathrm{~h}$ after cell proliferation arrest, stored at $4^{\circ} \mathrm{C}$ and used to launch ELF3 expressions $\left(\mathrm{V}_{2}\right)(500 \mathrm{~mL}$ cell cultures at $1.0 \times 10^{6}$ cells $/ \mathrm{mL}$ with $0.1 \%(\mathrm{v} / \mathrm{v}) \mathrm{V}_{1}$ virus $)$. Amplification of the virus and protein expression were followed by monitoring YFP (Yellow Fluorescent Protein) expression from the viral backbone and cells harvested $\left(2000 \mathrm{~g}, 15 \mathrm{~min}, 4^{\circ} \mathrm{C}\right)$ when reaching a fluorescence signal plateau. All experiments were performed at $27^{\circ} \mathrm{C}$.

\section{Protein Purification}

$\mathrm{LUX}^{\mathrm{FL}}, \mathrm{LUX}^{\mathrm{MYB}}$ and SeMet $\mathrm{LUX}^{\mathrm{MYB}}$ proteins were isolated following the same purification protocol. Harvested cells were resuspended in buffer A (200 mM CAPS pH 10.5, $500 \mathrm{mM} \mathrm{NaCl}, 1 \mathrm{mM}$ TCEP) to which benzonase and protease inhibitors were added. Cells were disrupted by sonication, followed by centrifugation for $40 \mathrm{~min}$. at $25000 \mathrm{rpm}$ and $4^{\circ} \mathrm{C}$. Cell lysates were applied onto a $1 \mathrm{~mL}$ Ni-Sepharose High-Performance resin (GE-Healthcare) column, pre-equilibrated with Buffer A. The column was then washed with $15 \mathrm{CV}$ of wash buffer (buffer A $+10 \mathrm{mM}$ imidazole) and the protein subsequently eluted with buffer B (buffer A $+200 \mathrm{mM}$ imidazole). Fractions of interest were pooled and dialysed overnight at $4^{\circ} \mathrm{C}$ against dialysis buffer (50 mM CAPS pH 9.7, $500 \mathrm{mM} \mathrm{NaCl}, 1 \mathrm{mM}$ TCEP) in the presence of $2 \%(\mathrm{w} / \mathrm{w})$ TEV protease, in order to cleave the $\mathrm{N}$-terminal $6 \mathrm{xHis}$ tag. The protein samples were then concentrated and buffer exchanged against buffer $\mathrm{C}$ (50 mM CAPS pH 9.7, $100 \mathrm{mM} \mathrm{NaCl}, 1 \mathrm{mM}$ TCEP) before being applied onto a $1 \mathrm{~mL}$ heparin column (GEHealthcare) and eluted against a $25 \mathrm{CV}$ salt gradient (buffer $\mathrm{D}$ : buffer $\mathrm{C}+1 \mathrm{M} \mathrm{NaCl}$ ). $\mathrm{LUX}^{\mathrm{MYB}}$ and SeMet LUX ${ }^{\mathrm{MYB}}$ fractions of interest were pooled after the heparin column, buffer exchanged with buffer $\mathrm{C}$ and concentrated to $5-10 \mathrm{mg} / \mathrm{mL}$, for crystallisation studies. As $\mathrm{LUX}^{\mathrm{FL}}$ exhibited poor binding to the heparin column, the flow through was collected, pooled, concentrated and passed over a size exclusion Superdex 200 10/300 GL column (GEHealthcare), pre-equilibrated with buffer $\mathrm{C}$, as a final purification step. $\mathrm{LUX}^{\mathrm{FL}}$ was concentrated to $14 \mathrm{mg} / \mathrm{mL}$.

For ELF4 protein, harvested cells were resuspended in $20 \mathrm{mM}$ Tris $\mathrm{pH} 8.0,500 \mathrm{mM}$ $\mathrm{NaCl}, 1 \mathrm{mM}$ TCEP (buffer E) to which benzonase and protease inhibitors were added. Cells were lysed by sonication, cell debris removed via centrifugation for $40 \mathrm{~min}$. at $18000 \mathrm{rpm}$ and $4^{\circ} \mathrm{C}$, and the supernatant applied onto a $1 \mathrm{~mL}$ Ni-Sepharose High-Performance resin column, pre-equilibrated with Buffer E. The column was washed with $25 \mathrm{CV}$ of wash buffer (buffer E $+20 \mathrm{mM}$ imidazole) and the protein eluted with buffer $\mathrm{F}$ (buffer $\mathrm{E}+200 \mathrm{mM}$ imidazole). Fractions of interest were pooled and dialysed overnight at $4^{\circ} \mathrm{C}$ against buffer $\mathrm{G}(20 \mathrm{mM}$ Tris $\mathrm{pH} 8.0,300 \mathrm{mM} \mathrm{NaCl}, 1 \mathrm{mM}$ TCEP) and in the presence of $2 \%(\mathrm{w} / \mathrm{w}) \mathrm{TEV}$ protease, in order to cleave the N-terminal 6xHis tag. The protein sample was then passed onto a second NiSepharose column (150 $\mu \mathrm{L}$ resin) in order to deplete 6xHis tagged TEV protease and subsequently applied to a size exclusion Superdex 200 Hi-Load 16/60 column (GE- 
Healthcare), pre-equilibrated with buffer $\mathrm{H}(20 \mathrm{mM}$ Tris pH 8.0, $100 \mathrm{mM} \mathrm{NaCl}, 1 \mathrm{mM}$ TCEP). Protein fractions were pooled and concentrated to $10-16 \mathrm{mg} / \mathrm{mL}$.

For ELF3 the cell pellet was resuspended in buffer I ( $8 \mathrm{M}$ Urea $+1 \mathrm{mM}$ TCEP) and lysed via four freeze/thaw cycles in liquid nitrogen and an ice/water bath. The cell lysate was then centrifuged for $1 \mathrm{~h}$ at $18000 \mathrm{rpm}$ and $4^{\circ} \mathrm{C}$ and the supernatant applied to a $0.5 \mathrm{~mL} \mathrm{Ni}$ Sepharose High-Performance resin column, pre-equilibrated in buffer I. The column was washed with $15 \mathrm{CV}$ of wash buffer (buffer I $+20 \mathrm{mM}$ imidazole) and the protein subsequently eluted with elution buffer (buffer I $+200 \mathrm{mM}$ imidazole). Fractions of interest were pooled and dialysed overnight at $4^{\circ} \mathrm{C}$ against $7 \mathrm{M}$ Urea $+1 \mathrm{mM}$ TCEP, followed by a $4 \mathrm{~h}$ dialysis against $6 \mathrm{M}$ Urea $+1 \mathrm{mM}$ TCEP. The protein sample was then concentrated up to 1$1.5 \mathrm{mg} / \mathrm{mL}$.

\section{Protein crystallisation and data collection}

A protein-DNA complex was prepared for SeMet derivatised LUX ${ }^{\mathrm{MYB}}$, using a 1:1.2 protein:DNA molar ratio. The 10-mer dsDNA sequence with a one base overhang on the 5' and 3' ends (forward oligo 5'-TAGATACGCA-3', reverse oligo 5'-ATGCGTATCT-3') was ordered as single stranded oligonucleotides (Eurofins). Equimolar concentrations of the two oligonucleotides were mixed, heated to $95^{\circ} \mathrm{C}$ for $5 \mathrm{~min}$., annealed and used without further purification. Crystallisation experiments were carried out by the vapour diffusion method at 293K, using sitting-drops with a 1:1 ratio of protein-DNA complex:precipitant with a protein concentration of $\sim 6 \mathrm{mg} / \mathrm{mL}$. Suitable well-diffracting crystals were grown after 2-4 days in $0.1 \mathrm{M}$ BisTris Propane, $\mathrm{pH}$ 6.5, 20\% PEG 3350 and $0.2 \mathrm{M}$ sodium malonate. Crystals grew as

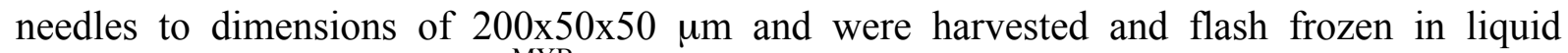
nitrogen. For the native LUX ${ }^{\mathrm{MYB}}$ structure with the DNA sequence (5'-TATATTCGAA-3', reverse oligo 5'-ATTCGAATAT-3') crystallisation conditions were the same as above. Crystallisation was performed by the EMBL High Throughput Crystallisation Facility (HTX).

Diffraction data were collected at 100K, on beamline ID29 at the European Synchrotron Radiation Facility (ESRF), Grenoble France. A data set was collected to $2.1 \AA$ at the peak absorbance of selenium (0.97886 $\AA$ ) (50). Indexing was performed using EDNA(56) and the default optimized oscillation range and collection parameters used for data collection. The data set was processed and scaled using the programs XDS and XSCALE.(57) The data were phased using SHELX (58). All refinements were performed using BUSTER (59). Final Ramachandran statistics were $100 \%$ preferred region for all residues. The structure is deposited under PDB code 5LXU. For the LUX ${ }^{\mathrm{MYB}}$ structure with the DNA sequence (5'TATATTCGAA-3', reverse oligo 5'-ATTCGAATAT-3') data were collected on beamline ID23-1 of the ESRF at $0.976 \AA$. Indexing was performed using EDNA(56) and the default optimized oscillation range and collection parameters used for data collection. The data set was processed and scaled using the programs XDS and XSCALE(57). Due to anisotropy of the data, the Global Phasing Limited STARANISO server was used for further data reduction and subsequent refinements (http://staraniso.globalphasing.org/cgi-bin/staraniso.cgi). All refinements were performed with Phenix. Final Ramachandran statistics were $100 \%$ preferred region for all residues. The structure is deposited under PDB code 6QEC. Data collection and refinement statistics are given in Table 2.

\section{Sequence Alignments}

Structure-based sequence alignments were performed using the server PROMALS3D (51). The three-dimensional structures of AtLUX (PDB 5LXU), AtARR10 (Arabidopsis thaliana Type-B Response Regulator 10, PBD 1IRZ), AmRAD (Antirrhinum majus RADIALIS, PDB 2CJJ), AtTPR1 (Arabidopsis thaliana Telomeric-Repeat-binding Protein 1, PDB 2AJE), HsDMP1 (Homo sapiens cyclin D-binding Myb-like TF 1, PDB 2LLK) and 
Mm_c-MybR1 and R2 (Mus musculus c-Myb Repeat 1 and 2, PBD 1GUU and 1GV5) were aligned with TM-align using the default parameters (52).

\section{Electrophoretic Mobility Shift Assays (EMSAs)}

A 36bp DNA oligonucleotide

$\left(5^{\prime}-\right.$

ATGATGTCTTCTCAAGATTCGATAAAAATGGTGTTG-3') from the $P R R 9$ promoter containing a LUX DNA-binding site (in bold and underlined) was used for EMSAs, and the core LBS mutated to yield different sequences:

\begin{tabular}{|l|l|}
\hline Oligo 1 & 5'-ATGATGTCTTCTCAAGATTCGATAAAAATGGTGTTG-3' \\
\hline Oligo 2 & 5'-ATGATGTCTTCTCAAGATACGCTAAAAATGGTGTTG-3' \\
\hline Oligo 3 & 5'-ATGATGTCTTCTCAAGATCTTATAAAAATGGTGTTG-3' \\
\hline Oligo 4 & 5'-ATGATGTCTTCTCGGATCCGATAAAAATGGTGTTG-3' \\
\hline Oligo 5 & 5'-ATGATGTCTTCTCGAATATTCGATAAAAATGGTGTTG-3' \\
\hline
\end{tabular}

All dsDNA oligonucleotides tested were Cy5 labelled (Eurofins Genomics). Protein concentration was varied from $0 \mathrm{nM}$ to $1000 \mathrm{nM}$ for $\operatorname{LUX}^{\mathrm{MYB}}$ and $\mathrm{LUX}^{\mathrm{FL}}(0 \mathrm{nM}, 2.5 \mathrm{nM}, 5.0$ $\mathrm{nM}, 15 \mathrm{nM}, 30 \mathrm{nM}, 60 \mathrm{nM}, 120 \mathrm{nM}, 250 \mathrm{nM}, 500 \mathrm{nM}$ and $1000 \mathrm{nM}$ ) using a constant DNA concentration of $10 \mathrm{nM}$ in all reactions. Protein and DNA were incubated at room temperature for $40 \mathrm{~min}$. in binding buffer $(10 \mathrm{mM}$ Tris $\mathrm{pH} 7.0,50 \mathrm{mM} \mathrm{NaCl}, 1 \mathrm{mM} \mathrm{MgCl} 2,1 \mathrm{mM}$ TCEP, $3 \%$ glycerol, $28 \mathrm{ng} / \mu \mathrm{L}$ herring sperm DNA (Roche), $20 \mu \mathrm{g} / \mathrm{mL}$ BSA, $2.5 \%$ CHAPS and 1.25 $\mathrm{mM}$ spermidine) and protein-DNA complexes $\left(\mathrm{LUX}^{\mathrm{FL}}\right.$ or $\mathrm{LUX}^{\mathrm{MYB}}$ ) run on a $8 \%$ polyacrylamide gel using TBE buffer $0.5 \mathrm{x}$ in non-denaturing conditions at $4^{\circ} \mathrm{C}$.

For LUX-ELF3 and LUX-ELF3-ELF4 experiments, all tested complexes were reconstituted by mixing the proteins of interest in $6 \mathrm{M}$ urea in dialysis buttons, followed by a step-wise dialysis in order to incrementally reduce the urea concentration to $0 \mathrm{M}$, allowing protein complex refolding $(6 \mathrm{M}, 5 \mathrm{M}, 4 \mathrm{M}, 2 \mathrm{M}, 1 \mathrm{M}$ urea $+1 \mathrm{mM}$ TCEP in 30 min. steps, and finally $50 \mathrm{mM}$ sodium phosphate $\mathrm{pH} 7.6+100 \mathrm{mM} \mathrm{NaCl}+1 \mathrm{mM}$ TCEP for one hour). LUX and ELF4 concentrations were $200 \mathrm{nM}$ and 0 or $1 \mu \mathrm{M}$, respectively, while the ELF3 concentration was varied from $220 \mathrm{nM}$ to $2.2 \mu \mathrm{M}$. The DNA oligomer used was from the PRR9 promoter and its concentration maintained constant at $30 \mathrm{nM}$ in all EMSA experiments. Proteins and DNA were incubated at room temperature for $40 \mathrm{~min}$. in binding buffer $(10 \mathrm{mM}$ Tris $\mathrm{pH} 7.0,1 \mathrm{mM} \mathrm{MgCl} 2,1 \mathrm{mM}$ TCEP, $6 \%$ glycerol, $28 \mathrm{ng} / \mu \mathrm{L}$ herring sperm DNA (Roche), $20 \mu \mathrm{g} / \mathrm{mL}$ BSA, $2.5 \%$ CHAPS and $1.25 \mathrm{mM}$ spermidine) and protein-DNA complexes (LUXELF3 and LUX-ELF3-ELF4) run on a $2 \%$ agarose gel using TBE buffer $0.5 \mathrm{x}$ in nondenaturing conditions at $4^{\circ} \mathrm{C}$. Gels were scanned using a Chemidoc scanner (Biorad).

\section{Plant material and cultivation conditions}

The lux-4 mutant allele (background accession Col-0) was provided by Dr. Philip Wigge, Sainsbury Lab, Cambridge University). Seeds of Col-0 and mutants were sterilized in 70\% ethanol and sown on 0.5 MS agar medium. For qPCR and hypocotyl measurements material was collected from 7-days old seedlings grown in FitoClima D1200 (Aralab) growth chambers, at $22^{\circ} \mathrm{C}$ (SD, 8h light/16h dark). Hypocotyl length was measured from images obtained from a flatbed scanner using Image software. Hypocotyl measurements were performed on the T2 generation of plants with 15-25 plants for each independent line. For flowering phenotype analysis, primary transformants were selected for the transgene and sown on soil and transferred to LD conditions after stratification $\left(4^{0} \mathrm{C}, 3\right.$ days). Flowering time was determined in randomly distributed plants according to number of rosette leaves at the time of bolting (10 plants for wild type, lux-4, lux-4 $\mathrm{p} L U X:: L U X^{R 146 A}$ and $\left.l u x-4 p L U X:: L U X\right)$ ). 


\section{Plasmid construction and generation of transgenic plants}

For the luX-4 pLUX::LUX ${ }^{R 146 A}$, lux-4 pLUX::LUX constructs, a $~ 800 \mathrm{bp}$ upstream fragment of $L U X$ was PCR-amplified from genomic DNA. Full length CDS of LUX and $L U X^{R 146 A}$ were PCR-amplified from the pESPRIT002 expression vector containing the respective CDS with an N-terminal FLAG tag added (SI Figure 2). NEBuilder® HiFi DNA Assembly Kit (E2621S, NEB) was used for assembling the promoter fragment with the appropriate cDNA fragment, FLAG tag and vector backbone (pFP101 containing the At2S3 promoter driven GFP for selection of transformants)(57). For a list of primers see Supplemental Table 1. Transgenic plants were generated by Agrobacterium-mediated gene transfer using the floral dip method (58). Lux-4 plants were dipped with Agrobacterium containing $p L U X:: L U X^{R 146 A}$ or $p L U X:: L U X$ constructs to obtain lux-4 pLUX::LUX $X^{R 146 A}$ and lux-4 pLUX::LUX plants.

\section{RNA isolation and quantitative PCR}

Plants were grown under short day conditions (8L:16D) for 7 days in $0.5 \mathrm{MS}$ media and samples were harvested in intervals of 4 hours. 8-10 seedlings were harvested for each line at each time point. Total RNA was extracted using RNeasy Plant mini kit (Qiagen) according to manufacturer's instructions. Total RNA (1 $\mu \mathrm{g})$ was treated with DNaseI (Roche) qRT-PCR was done using iTaq ${ }^{\circledR}$ Universal SYBR® Green One-Step Kit from Bio-Rad following manufacturer's protocol. For the list of primers see SI Table 1. Expression of PIF4 in different plant lines was determined through qRT-PCR with PP2A used as a control. qRT-PCR measurements were performed with a Bio-Rad CFX connect Real-Time system. Quantification was performed with the relative $-\Delta \mathrm{Ct}$ method, using $P P 2 A$ for normalization. All quantification and statistical analysis were performed using CFX Maestro ${ }^{\mathrm{TM}}$ software (Bio-Rad). 
bioRxiv preprint doi: https://doi.org/10.1101/584854; this version posted March 21, 2019. The copyright holder for this preprint (which was

not certified by peer review) is the author/funder. All rights reserved. No reuse allowed without permission. 